\title{
What Do We Know About Neuropsychological Aspects Of Schizophrenia?
}

\author{
Barton W. Palmer • Sharron E. Dawes • \\ Robert K. Heaton
}

Received: 25 March 2009 / Accepted: 2 July 2009 /Published online: 30 July 2009

(C) The Author(s) 2009. This article is published with open access at Springerlink.com

\begin{abstract}
Application of a neuropsychological perspective to the study of schizophrenia has established a number of important facts about this disorder. Some of the key findings from the existing literature are that, while neurocognitive impairment is present in most, if not all, persons with schizophrenia, there is both substantial interpatient heterogeneity and remarkable within-patient stability of cognitive function over the long-term course of the illness. Such findings have contributed to the firm establishment of neurobiologic models of schizophrenia, and thereby help to reduce the social stigma that was sometimes associated with purely psychogenic models popular during parts of the 20th century. Neuropsychological studies in recent decades have established the primacy of cognitive functions over psychopathologic symptoms as determinants of functional capacity and independence in everyday functioning. Although the cognitive benefits of both conventional and even second generation antipsychotic medications appear marginal at best, recognition of the primacy of cognitive deficits as determinants of functional disability in schizophrenia has catalyzed recent efforts to develop targeted treatments for the cognitive deficits of this disorder. Despite these accomplishments, however, some issues remain to be resolved. Efforts to firmly establish the specific neurocognitive/neuropathologic systems responsible for schizophrenia remain elusive, as do efforts to definitively demonstrate the specific cognitive deficits underlying specific forms of functional impairment. Further progress may be fostered by recent initiatives to integrate neuropsy-
\end{abstract}

B. W. Palmer $(\bowtie) \cdot$ S. E. Dawes $\cdot$ R. K. Heaton

University of California, San Diego,

9500 Gilman Drive 0603V,

La Jolla, CA 92093-0603, USA

e-mail: bpalmer@ucsd.edu chological studies with experimental neuroscience, perhaps leading to measures of deficits in cognitive processes more clearly associated with specific, identifiable brain systems.

Keywords Psychoses $\cdot$ Cognitive $\cdot$ Heterogeneity · Activities of daily living $\cdot$ Historical

\section{Introduction}

Schizophrenia is now almost universally recognized as a neurobiological disorder with a strong neurocognitive component (Harrison and Weinberger 2005; Keshavan et al. 2008). In contrast to earlier cognitive studies of schizophrenia that were frequently focused on distinguishing schizophrenia from "brain damage" (reviewed in Heaton et al. 1978), or on the description of schizophrenic thinking on a strictly psychological level (e.g., Bolles and Goldstein 1938; Cameron 1939a, 1939b; Payne et al.1959; Vigotsky 1934), an enormous and still growing body of neuropsychological research on schizophrenia over the last few decades has been based largely on either of two premises: (a) specification of the neurocognitive pattern(s) associated with schizophrenia may help clarify the neuroanatomic and/or neurophysiologic systems that underlie expression of schizophrenia (Levin et al. 1989), and/or (b) recognition that identifying cognitive strengths and weaknesses within persons with schizophrenia, and the relationship of such cognitive abilities/deficits to psychosocial or independent living functions, might prove clinically useful in developing effective placement and rehabilitative plans (Green 1996; Heaton 1976; Heaton and Pendleton 1981).

In this paper, we consider the recent empirical literature to inform an overview of the neuropsychological aspects of schizophrenia. Following some brief historical comments, 
we will focus the remainder of our review on the following questions: (1) What cognitive domains are affected by schizophrenia? (2) How much intragroup heterogeneity exists? (Do all persons with schizophrenia have cognitive impairment, and are there reliable cognitive subtypes?) (3) What is the premorbid, peri-onset, and long-term course of cognitive functioning in schizophrenia? (4) What is known about neuropathological systems which may underlie cognitive dysfunction in schizophrenia? (5) What are the effects of general and specific cognitive deficits on patients' independence in everyday functioning? and (6) What is the effectiveness of current pharmacologic treatments for cognitive deficits in schizophrenia? (We also briefly describe recent efforts to develop non-pharmacologic interventions for the cognitive deficits of schizophrenia; however, see Medalia and Choi (2009), this volume, for a comprehensive review of cognitive remediation in schizophrenia.)

\section{Historical Evolution of Neurocognitive Models of Schizophrenia}

There is now overwhelming empirical evidence that schizophrenia is fundamentally a neurobiologic disorder (Harrison and Weinberger 2005; Keshavan et al. 2008), and one that is at least usually (albeit, as discussed below, perhaps not invariably) accompanied by neurocognitive deficits (Dickinson et al. 2007; Fioravanti et al. 2005; Heinrichs and Zakzanis 1998). Nevertheless, this contemporary view of the disorder represents a relatively recent resolution of a sometimes heated debate over the past century about the "functional" versus "organic" nature of schizophrenia (Babcock 1933; Bleuler 1930; Leonberger 1989; May 1931; Paris 2005; Spielmeyer 1930; Walker and Tessner 2008).

Emil Kraepelin, the first to distinguish schizophrenia (dementia praecox) from other forms of serious mental illness, held a strongly neurobiologic conceptualization of this disorder. As early as 1899 he commented that "From the known clinical and anatomical facts [of dementia praecox] I cannot doubt that we have to do here with a severe and as a rule markedly retrogressive process in the brain cortex" (as translated and cited by May (1931) p. 408). In the 1913 edition of his classic textbook, Kraepelin (1971/1919/1913) discussed possible biological as well as psychosocial causes of dementia praecox, including a number of potential factors which anticipate contemporary neurodevelopmental models of schizophrenia (cf. Rapoport et al. 2005), such as hereditary predisposition and "injury to the germ" (prenatal injury), as well as commenting on minor facial and other physical anomalies which exist "with striking frequency" among such patients (p. 236). (The latter are currently thought to reflect parallel prenatal aberrations in neurodevelopment (Weinberg et al. 2007).)

Anticipating that regions of interest in contemporary neuroanatomic theories of schizophrenia would be focused, in part, on the frontal-subcortical and temporal lobe regions or systems (Harrison 2004; Ragland et al. 2007; Shad et al. 2006; Winterer et al. 2003); Kraepelin (1971/ 1919/1913) noted that "If it should be confirmed that the disease attacks by preference the frontal areas of the brain, the central convolutions, and the temporal lobes, this distribution would in a certain measure agree with our present views about the site of the psychic mechanisms which are principally injured by this disease" (p. 219). Kraepelin also characterized dementia praecox as a dysfunction in what would today be labeled "executive functions," particularly in regard to deficits of "volition" or "will" (see Zec 1995).

Despite such strong beginnings toward a neurobiologic model of schizophrenia, the first half and even early second half of the 20th century evidenced considerable debate regarding psychogenic (or "functional") versus biological ("organic") models of schizophrenia (Babcock 1933; Bleuler 1930; Leonberger 1989; May 1931; Paris 2005; Spielmeyer 1930; Walker and Tessner 2008). There were a number of empirical reports documenting cognitive deficits among persons with schizophrenia, particularly in regard to deficits in abstraction, conceptualization, or a tendency toward overgeneralization (e.g., Bolles and Goldstein 1938; Cameron 1939b; Fey 1951; Payne et al. 1959; Rawlings 1921; Vigotsky 1934). With some exceptions (e.g., Babcock 1933; e.g., Rawlings 1921; Wittman 1937), the latter tended to be focused on a purely psychological level of description of the structure of schizophrenic thinking, i.e., with limited presumption or reference to neuropathologic mechanisms (see reviews by Lothrop (1961) and Wright (1975)).

Even Kurt Goldstein, one of the pioneers of neuropsychology and the use of psychometric tests to study the effects of brain damage (see historical reviews by G. Goldstein 1990a, 2009), and someone well aware of the effects brain damage can have on abstraction ability (Goldstein 1949; Goldstein and Scheerer 1941), emphasized the psychological, not neurobiologic, aspects of what he called the impairment in "abstract attitude" among persons with schizophrenia (Bolles and Goldstein 1938; Goldstein 1939, 1959). Some of his musings about the potential neuropathology underlying schizophrenia appear remarkably contemporary. For example, he wrote that "There is no doubt that the clinical picture of schizophrenia contains symptoms which may best be understood as expressions of a disturbed function of some apparatus of the brain, particularly of the frontal lobes and the 
subcortical ganglia...” (Goldstein 1939, p. 582). Yet, his emphasis in describing and explaining cognitive concreteness in schizophrenia remained solidly on the psycholog$\mathrm{ical} / \mathrm{psychodynamic} \mathrm{level.} \mathrm{Indeed,} \mathrm{in} \mathrm{a} \mathrm{later} \mathrm{commentary,} \mathrm{K}$. Goldstein (1959) noted his opinion that the abnormal concreteness in schizophrenia "is not the effect of an organic defect" (italics in original; p. 147), but rather "a protective mechanism against anxiety which originated in early youth" (italics in original; p. 147).

As noted above, the other primary impetus in early and mid-20th century studies of cognitive test performance in schizophrenia was to identify test performance patterns that would reliably discriminate patients with documented brain lesions ("true organicity") from those with schizophrenia (reviewed in Heaton et al. 1978). Commenting on the difficulties in finding useful discriminatory patterns, Watson et al. (1968) wrote "It would appear that the chronic schizophrenic's motivational deficits and thought disorders, coupled with the recovery shown by some organics, eliminate many of the test differences psychologists have expected to separate members of the two groups" (p. 679). The latter quote demonstrates that, even through the late 1960s, at least some researchers interpreted deficient performance by patients with schizophrenia on neuropsychological tests as reflecting deficits engaging in the tasks (due to psychotic symptoms and motivation problems), rather than reflecting genuine neurocognitive impairment.

Finally, in the last quarter of the 20th century, neuropsychology began to take more frequent, albeit initially somewhat diffident, steps in asserting the fact that schizophrenia is fundamentally a brain disorder. For instance, Strauss and Silverstein (1986) commented that "Recent evidence has raised a question of a central nervous system basis for schizophrenic psychopathology" [underline added for emphasis] (p. 35). Although the potential role of psychosocial stress in the phenotypic manifestation of schizophrenia is still generally recognized (Walker and Tessner 2008; Zubin and Spring 1977), the last quarter century brought a clear, empirically grounded change in the zeitgeist away from purely psychogenic models of schizophrenia and other forms of serious mental illness (Paris 2005; Walker and Tessner 2008). This change included an exponential growth in the empirical study of schizophrenia from a neuropsychological perspective (Levin et al. 1989).

\section{Level and Domains of Cognitive Impairment}

The extant neuropsychological literature relevant to establishing the level of cognitive impairment associated with schizophrenia is truly enormous. Fortunately, there have been a number of excellent meta-analytic reviews published over the past decade, integrating the literature comparing test performance among schizophrenia patients and healthy comparison subjects (Dickinson et al. 2007; Fioravanti et al. 2005; Heinrichs and Zakzanis 1998; Mesholam-Gately et al. 2009). In addition to their own meta-analytic review of individual studies, Dickinson et al. (2007) provided a Table (i.e., their Table 4, p. 538) that serves as a summary of meta-analytic reviews (see also Reichenberg and Harvey 2007). The general conclusion that can be drawn from this literature is quite clear: schizophrenia is best characterized as involving broad neurocognitive deficits across most cognitive domains.

The average cognitive deficit associated with schizophrenia appears to be approximately one standard deviation (SD) below the mean of healthy comparison subjects (Dickinson et al. 2007). In regard to specific cognitive domains, the general trend in the literature seems to be that the strongest effect sizes are associated with tests of episodic memory (particularly free recall), and processing speed, with the least (but still medium to large effect size differences) associated with measures of crystallized verbal knowledge and visual-spatial skill. For instance, among studies reviewed by Heinrichs and Zakzanis (1998), the lowest mean effect sizes were seen with the Wechsler Block Design $(d=0.46)$ and Vocabulary $(d=0.53)$ subtests; the strongest mean effect size was seen on tests of "Global Verbal Memory" ( $d=1.41)$. Similarly, among studies reviewed by Fioravanti et al. (2005), the largest effect sizes were associated with tests of memory $(d=1.18)$, and the lowest with tests of language function $(d=1.01)$ and global cognitive function or IQ $(d=1.01)$. In their recent metaanalysis of studies of persons in their first-episode of schizophrenia, Mesholam-Gately et al. (2009) also found the largest effect sizes, on average, to be associated with tests in the domain of auditory memory $(d=1.20)$; although among individual tests, the largest effect size was that for Digit Symbol $(d=1.59)$. The smallest effect sizes were in the domain of motor speed and dexterity $(d=0.64)$; although on the level of individual test scores, some of the smallest effect sizes were those associated with specific aspects of California Verbal Learning Test Performance, particularly "storage" $(d=0.34)$. Dickinson et al. (2007) also found the strongest effect sizes were those from the Digit Symbol task $(d=1.57)$, and auditory episodic memory tests tended to have the next highest effect sizes (ds $=1.09$ to 1.25 ). Some of the smallest effect sizes among studies reviewed by Dickinson et al. (2007) were Block Design $(d=0.84)$, Line Orientation $(d=0.62)$, and Word Reading $(d=0.59)$. Yet, note that even at the lower end, the effect size ranges in these various reviews are near the cut-off of $d=0.50$ commonly labeled a "medium" effect, while many others are above the $d=0.80$ cut-off commonly labeled as a "large" effect size (Cohen 1988). 
In addition to memory impairment, there has been considerable interest in the neuropsychological literature focused on working memory and executive functions. Among the meta-analyses reviewed by Dickinson et al. (2007), the mean effect sizes for executive function tests (Wisconsin Card Sorting Test, Stroop Color Word Interference, and Trail Making Part B) range from $d=0.53$ to $d=$ 1.06; for letter and category fluency (which were listed separately), the effect sizes ranged from $d=0.99$ to 1.41 ; and for working memory (including Digit Span forward and backward, mental Arithmetic, Letter Number Sequencing, and other measures of verbal or visual-spatial working memory), the effect sizes ranged from 0.61 to 1.18. (For sake of consistency, we have labeled the effect sizes with "d" from Cohen's d, but Dickinson et al. used a modification which adjusts for small sample sizes, Hedges'g). In short, although executive functions and working memory are typically affected by schizophrenia, the empirical data do not point to differential impairment in these ability areas (Braff et al. 1991).

From the pattern of effect sizes reviewed above, one might be tempted to conclude that episodic memory deficits are in some sense an especially important or "core" cognitive deficit in schizophrenia. However, the perennial interpretive problem, brought by a lack of established psychometric equivalence in sensitivity and specificity of measures of different cognitive constructs, remains largely unresolved (Chapman and Chapman 1973). Moreover, as also is true of "attention" and "executive functions," the term "memory" is non-specific (Squire 2004). For instance, it appears that the bulk of test scores contributing to the large mean effect size for "memory," reported in the studies reviewed by Heinrichs and Zakzanis (1998), consisted of free recall scores on tests of verbal episodic memory. In stark contrast to the pattern seen with Alzheimer disease (Tröster et al. 1993) patients with schizophrenia do not typically show rapid forgetting of information actually learned (Heaton et al. 1994; Paulsen et al. 1995). In a meta-analysis specifically focused on memory test results, Aleman et al. (1999) found an effect size for total recall of $d=1.21$, whereas that for recognition scores was only half as strong $(d=0.64)$.

Further reason for caution in drawing conclusions about differential "core" deficits was provided by Fioravanti et al. (2005), who noted the considerable heterogeneity in effect sizes seen between studies. (A similar observation was made by Mesholam-Gately et al. (2009) in regard to studies of first episode patients.) Fioravanti et al. (2005) attributed the inter-study heterogeneity in effect sizes to both a lack of cross-study consistency in methodology (including variation in the sensitivity of the specific measures employed to operationalize various constructs, and variation in the procedures for selecting and matching of healthy compar- ison subjects), and to differences in the characteristics of the patient samples. In regard to the latter, Fioravanti et al. asserted that "Our analysis of heterogeneity indicates that there has been a widespread failure to consider the multidimensional nature of this patient population" (p. 90). Thus, rather than endeavoring to establish the deficits of a non-existent "average" patient with schizophrenia, it may be more fruitful to consider the issue of cognitive heterogeneity in level and pattern of impairment and the factors which do or do not coaggregate with better/worse or different patterns of impairment.

\section{Heterogeneity}

Do all persons with schizophrenia have cognitive impairment? In the mid-1980s, there were several reports indicating some patients with schizophrenia are "neuropsychologically intact" (Bryson et al. 1993; Silverstein and Zerwic 1985; Strauss and Silverstein 1986), and more recent studies indicate that approximately $15 \%$ to $30 \%$ (with most estimates between $20 \%$ to $25 \%$ ) of schizophrenia patients have neuropsychological profiles in the normal range (Allen et al. 2003; Goldstein 1990b; Heinrichs and Awad 1993; Holthausen et al. 2002; Ilonen et al. 2004; Kremen et al. 2000; Leung et al. 2008; Liu et al. 2006; Palmer et al. 1997; Weickert et al. 2000). For instance, using a previously validated procedure for systematic clinical ratings of results from an expanded HalsteadReitan battery (Heaton et al. 1981), we found 47 of the 171 (27.5\%) people with schizophrenia had "neuropsychologically normal" profiles (Palmer et al. 1997). By way of comparison, Kremen et al. (2000) used a similar clinical rating procedure, albeit with a different neuropsychological test battery, and classified 17 of 75 (22.7\%) schizophrenia patients as "neuropsychologically within normal limits."

The larger literature examining the association between severity of cognitive deficits and psychopathologic symptoms is consistent in showing a significant but modest association between severity of cognitive deficits and negative symptoms, but no discernable association between cognitive deficits and positive symptoms, such as hallucinations and delusions (see de Gracia Dominguez et al. 2009). Comparisons of neuropsychologically normal versus neuropsychologically impaired patients with schizophrenia yield results generally consistent with this overall pattern. For instance, relative to neuropsychologically impaired patients, the neuropsychologically normal patients in our study had significantly less negative symptoms and extrapyramidal symptoms, and reported more frequent social contacts, as well as being less likely to have had a psychiatric hospitalization in the year preceding evaluation (Palmer et al. 1997). Other than the preceding variables, 
however, the neuropsychologically normal and impaired patient groups were comparable in most of the demographic, symptomatic/clinical, and functional characteristics. Similarly, Kremen et al. (2000) found that, relative to neuropsychologically impaired patients, those who were classified as "neuropsychologically within normal limits" had a trend $(p<.06)$ toward less negative symptoms, but no difference in reality distortion or disorganized symptoms. The neuropsychologically impaired patients in the latter study also had worse mean scores on a global assessment of psychosocial functioning, a lower proportion of paranoid subtype, earlier age of onset, and longer duration of illness. Leung et al. (2008) compared older schizophrenia patients in terms of neuropsychologically normal status; they found no significant differences among neuropsychologically normal versus impaired patients in regard to overall symptom status (or age).

Although the lack of group differences in severity of positive symptoms suggests that neuropsychologically normal status cannot be attributed to simple differences in overall disease severity, "neuropsychologically normal schizophrenia" is not necessarily synonymous with "neuropsychologically unaffected by schizophrenia" (Kremen et al. 2000). As a group, neuropsychologically normal persons with schizophrenia tend to have better than average performances on word reading tasks and/or other measures of crystallized verbal knowledge (Kremen et al. 2000; Wilk et al. 2005), and/or other characteristics commonly used to estimate "premorbid" functioning, such as maternal education (Keefe et al. 2005). Based on such findings, some investigators have suggested that "neuropsychologically normal" schizophrenia patients have in fact experienced a decline in cognitive functioning relative to an even higher premorbid level or potential.

It should be noted that current above average performance on tests of crystallized verbal ability, even relative to one's own other cognitive abilities, does not necessarily indicate a pathological cognitive profile and/or that the nonverbal abilities are below what they would be in the absence of schizophrenia. For instance, Heinrichs et al. (2008) compared the cognitive profiles of "verbally superior" schizophrenia patients (defined by a WAIS-IIII Vocabulary subtest Scaled Score $\geq 14$ ) to those of verbally superior healthy comparison subjects, as well as to verbally not superior healthy comparison subjects and patients with schizophrenia. The authors found no significant differences in the mean cognitive profiles among the verbally superior patients relative to the verbally superior healthy comparison subjects. Educational history, another potential proxy for premorbid function, was measured in reference to the proportion of subjects who were high school graduates. There were no significant differences in the high school graduation rates among verbally superior patients (96\%), verbally superior comparison subjects $(100 \%)$, or verbally not superior comparison subjects $(92 \%)$, whereas the verbally not-superior patient group had a significantly lower proportion of high school graduates (62\%). As the mean age of onset in both patient groups was approximately 20.6 years (with no significant differences between these two groups), the lower rates of high school graduates among the verbally not superior patients may simply reflect the premorbid cognitive deficits often associated with this disorder (discussed below). On the other hand, despite the fact that verbally superior patients and comparison subjects were equivalent in cognitive profiles and educational background, this study found no significant differences between the verbally superior and not verbally superior patient groups in regard to severity of positive, negative, or general symptoms, medication status, age of onset, or current employment rates (the latter was lower in both groups relative to the rates in both healthy comparison groups). In short, verbally superior/neuropsychologically normal status among schizophrenia patients did not equate with less severe psychopathology or with less occupational impairment.

Another potential method of examining the cognitive deficits associated with the phenotypic manifestation of schizophrenia is to study the degree of concordance in cognitive functioning among monozygotic twins discordant for schizophrenia. Reports of such data have been rare, but the twin-pair level cognitive concordance rates were provided through one of the published reports from the NIMH Twin Study. Specifically, Torrey et al. (1994) observed:

“... 3 of the 27 affected discordant twins were severely neuropsychologically impaired, performing significantly below their well co-twin on virtually all tests. An additional 11 affected twins were moderately impaired, performing significantly below their cotwins on at least 2 of the 5 functions that most clearly differentiated the affected twins (attention, memory, problem-solving, information processing, and verbal fluency)... Ten affected twins were less neuropsychologically impaired, and 3 affected twins [11\%] showed minimal or no neuropsychological impairment...some impairment in cognitive function, therefore, is present in almost all the affected twins with schizophrenia and not just a small subgroup of them" [underline added for emphasis] (p. 124).

The finding of three of 27 affected twins with minimal or no neuropsychological impairment clearly represents too small a sample to confidently or reliably estimate the precise frequency of a population parameter, and the NIMH investigators' emphasis in the above quote was clearly on the ubiquity of neurocognitive impairment in schizophre- 
nia. Nonetheless, the presence of the three of 27 affected twins with "minimal or no neuropsychological impairment" relative to the well co-twin is at least consistent with the notion that some neuropsychologically normal patients may in fact be functioning at or very close to the same level they would have in the absence of manifesting the clinical syndrome of schizophrenia. With the exception of an earlier report of 16 twin pairs from the same NIMH Twin study (Goldberg et al. 1990), to our knowledge, the only published report to describe the overall cognitive concordance rates among monozygotic twins discordance for schizophrenia was that provided by Kremen et al. (2006). They compared concordance in premorbid cognitive functioning among 21 middle-aged monozygotic military veteran twin pairs, currently discordant for schizophrenia, all of whom had completed the Armed Forces Qualification Test (AFQT) several decades earlier as part of their induction into the military. They found that $67 \%$ of the affected twins had lower (premorbid) AFQT scores than their well twin. Stated another way, about one-third of affected twins in monozygotic twin pairs discordant for schizophrenia had a level of premorbid cognitive function that was at least as good as that of their well twin.

Although the findings of Heinrichs et al. (2008), described above, illustrate that the presence of a relative strength in crystallized verbal knowledge is not synonymous with presence of even subtle deficits in other neurocognitive domains relative to some hypothetical higher potential level, it does seem likely that some unknown proportion of "neuropsychologically normal" people with schizophrenia do indeed manifest cognitive skills at a level lower than they might have otherwise been capable of in the absence of having developed schizophrenia. Thus, there may be two types of neuropsychologically normal patients with schizophrenia: (a) some proportion, such as the three of 27 affected twins in the NIMH twin study (Torrey et al. 1994), who show no apparent decline associated with the phenotypic expression of schizophrenia, at least when tested with common neuropsychological instruments, and (b) some proportion who have in fact experienced a decline (within a published normal range on the tests) relative to what the individual's cognitive capacity would have been in the absence of having developed schizophrenia. The likely existence of the latter type of neuropsychologically normal persons with schizophrenia seems at least partially consistent with established theories of brain or cognitive reserve (Satz 1993; Stern 2002). Yet, based on those same cognitive or brain reserve theories, one might ask: Why was there sufficient reserve to avoid functionally disabling cognitive deficits, but insufficient reserve to avoid functionally disabling psychopathologic deficits? Empirical efforts to address such questions through further fine-grained study of neuropsychologically normal schizophrenia patients, perhaps using both structural and functional neuroimaging methods, might provide insights into still unresolved issues such as: (a) Which neurobiologic systems underlie the cognitive deficits, which underlie psychopathologic symptoms, and how much overlap/separation is their between these systems? (b) Are there identifiable "thresholds" of function/dysfunction in these systems which predict whether or not disabling levels of psychopathology and/or cognitive dysfunction are expressed? and (c), Is there a causal link between some forms of cognitive dysfunction and certain psychopathologic symptoms, such as working memory deficits and thought disorder (Goldman-Rakic 1994)?

A recent structural neuroimaging study by Wexler et al. (2009) provides an illustrative example of how the concept of "neuropsychologically normal schizophrenia" may prove useful as part of ongoing efforts to elucidate the neuropathological bases of schizophrenia in general. Using structural MRI, these authors compared grey matter, white matter, and ventricular volumes among 21 "neuropsychologically near normal" persons with schizophrenia, 54 "neuropsychologically impaired" persons with schizophrenia, and 30 healthy comparison subjects. Both schizophrenia patient groups had smaller gray matter volumes and larger third ventricles relative to healthy comparison subjects. Compared to "neuropsychologically near normal" schizophrenia patients, the neuropsychologically impaired patients had smaller white matter volumes and larger lateral ventricles. However, in several brain regions, the neuropsychologically near normal patients had smaller gray matter volumes than the neuropsychologically impaired patients. If replicated, such results may indicate that the neuropathology associated with neuropsychologically normal schizophrenia represents a difference in kind/quality of neuropathology, rather than a simple difference in degree or severity of neuropathology.

As cogently argued by Allen et al. (2003), regardless of whether neuropsychologically normal schizophrenia patients have experienced slight declines from an even higher potential or premorbid level, study of the nature of (and factors underlying) manifest impairments in psychosocial functioning may provide greater clarity in regard to the non-cognitive contributions to impairment in everyday functioning. A recent example of research efforts in this vein was provided by the study of Leung et al. (2008), who focused on the differences between neuropsychologically normal versus impaired schizophrenia groups in reference to three markers of "real world" functional status (independent residential status, employment, and marital status), as well as social competence and overall functional capacity (measured via performance-based tasks). There were no group differences in severity of psychopathology, but relative to the neuropsychologically impaired patients, 
those who were neuropsychologically normal showed better scores on a performance-based measure of social competence and a measure of overall functional capacity, and were more likely to have independent living status. On the other hand, there were no group differences in employment or marital status. Note that findings regarding the lack of effects of neuropsychologically normal profiles on work status are consistent with those of Heinrichs et al. (2008), described previously. We also obtained similar findings from a study of predictors of functional status among middle-aged and older patients with schizophrenia (Palmer et al. 2002), i.e., there were significant correlations between cognitive test performance and level of independence in everyday functioning, but no significant correlation between cognitive performance and work history. Such findings warrant follow-up through replication of the study, but may indicate that work functioning is particularly vulnerable to a variety of non-cognitive as well as cognitive influences (cf. Green et al. 2000). The general issue of the association of neuropsychological deficits with everyday functioning is considered in greater detail in a separate section to follow.

Cognitive subtypes: Another approach to the question of cognitive heterogeneity in schizophrenia has been to use cluster analyses to identify general cognitive subgroups. Most cluster analytic studies (e.g. Allen et al. 1998; Goldstein et al. 1998; Heinrichs and Awad 1993; Hill et al. 2002; Horan and Goldstein 2003; Seaton et al. 1999) find approximately four clusters that usually contain one neuropsychologically normal cluster and one severely and broadly impaired cluster. The other two clusters vary in their profiles but are usually impaired (with differing degrees of severity), and show perhaps one or two areas of neuropsychological functioning as "stand out" impairments (e.g., motor, verbal memory, or executive functioning). For example, Horan and Goldstein's (2003) middle two clusters included one described as moderate overall impairment with severe motor impairment and the other with moderate impairment in all areas, whereas Heinrichs and Awad (1993) found five clusters with the three intermediate clusters being described as (1) especially impaired executive functioning, (2) especially impaired executive functioning and motor abilities, and (3) especially impaired motor abilities. Such findings are usually based on some iterative procedure (e.g., Ward's (1963) method) on data that may have been reduced in some manner (e.g., principal components analysis) into neurocognitive domains (e.g., abstraction/executive functioning, attention, verbal and visual memory, verbal and visuospatial abilities, motor skills, and working memory). However, there are some interpretive limitations associated with cluster analyses. The cluster determination may be arbitrary, depending on the methods employed. Methods are varied and there is little consensus as to the best method to employ, which may lead to differing results (Lange et al. 2002). Also, the clusters derived are often based upon overall level of performance rather than pattern based, which in some respects may not be very helpful in identifying "differences in kind" (Lange et al. 2002). There are ongoing advances in analytic techniques and approaches such as finite mixture modeling or factor mixture modeling which have not been widely applied to cognitive heterogeneity in schizophrenia but may yield additional insights (McLachlan and Basford 1988).

When studies have examined the associations between clinical or demographic factors and cluster membership, most found that clinical characteristics (e.g. dose of antipsychotic or positive or negative symptoms; Reichenberg and Harvey 2007) were not related, whereas some demographics (e.g., education) were different between clusters (Seaton et al. 1999). Heinrichs et al. (1997) examined differences between cognitive cluster groups on a modified version of the Sickness Impact Profile (SIP). The SIP is a self-report measure that provides ratings of self-perceived health, quality of life, sleep and rest, home management, social interaction, and recreation activities. The authors found that persons in the "normative" (generally intact) cognitive group had better sleep and rest relative to those in an "executive-motor" subtype (characterized by impaired WCST and Purdue Pegboard scores), whereas the selective executive group (characterized by isolated impairment only on the WCST) reported better home management, social interaction, and recreation than the executive-motor group, as well as better social interaction relative to those with generalized cognitive impairment. However, the sample sizes for these analyses were relatively small (total $N=55$ ); there is clearly a need for additional research that is sufficiently powered to detect functionally relevant differences and that employs multiple measures of functional capacity and functional status. (The issue of the association between cognitive deficits and everyday functioning is considered in greater detail below.)

Allen et al. (2000) examined the relationship of cognitive and symptom cluster subgroups to brain structure, measured with computerized tomography (CT) scans. They found no significant differences among the cognitive cluster groups in reference to ventricular size; however, global sulcul widening was highest among patients in the severely impaired cognitive cluster. In contrast, when comparisons were made among symptom-based clusters, participants in the predominantly negative symptoms cluster had larger third ventricle diameters relative to those in the mixed and positive symptom clusters. Allen et al. concluded that symptom and cognitive abnormalities in schizophrenia may have different neuropathological cor- 
relates. As also noted by Seaton et al. (2001): "Ultimately, the most likely typology to be successful will involve a combination of cognitive, symptom, and neuroimaging variables" (p. 47).

\section{Course}

Premorbid cognitive functioning: There is compelling evidence that schizophrenia is associated with early premorbid cognitive deficits. For example, Bilder et al. (2006) compared premorbid school transcripts, as well as college aptitude test scores, from first-episode inpatients with schizophrenia relative to those of healthy comparison subjects. Comparison of the available school transcripts suggested that, even in the first grade, children who later developed schizophrenia manifested an average grade equivalent score approximately 0.8 year lower than healthy comparison subjects (selected to have a similar distribution of age and gender) who did not develop schizophrenia. Comparison of college aptitude test scores (administered in grades 11 or 12) also indicated a premorbid deficit, relative to healthy comparison subjects, of almost one SD.

One caveat in interpreting Bilder et al.'s (2006) results regarding school transcript and college aptitude test comparisons is that the healthy comparison groups had higher mean parental social class scores than the patient group (based on the Hollingshead-Redlich Index (Hollingshead and Redlich 1958); also the healthy comparison group had a higher proportion of Caucasians (approximately 49\% of patients and $83 \%$ of healthy comparison subjects were of Caucasian background). The degree to which these socioeconomic and demographic differences affect the validity of the archival scores in establishing premorbid cognitive function is uncertain. Nonetheless, the overall pattern in the literature is generally consistent with the findings from Bilder et al.

Results of two meta-analytic reviews of studies documenting premorbid IQ among persons who subsequently developed schizophrenia suggest presence of at least a mild premorbid cognitive deficit, with an average premorbid Full Scale IQ of 90 to 95 compared to the population mean of 100, with SD of 15 (Aylward et al. 1984; Woodberry et al. 2008). For instance, Woodberry et al. (2008) reviewed 18 studies in which people who later developed schizophrenia, as well as healthy comparison subjects, had received standardized IQ or similar psychometric tests (studies focused on achievement tests were excluded) and found a lower premorbid IQ with a medium effect size $(d=0.54)$ among people who later developed schizophrenia. Woodberry et al. noted that this effect size is approximately half the effect size found in comparison of IQ when measured among post-onset schizophrenia patients relative to healthy comparison subjects (Dickinson et al. 2007; Heinrichs and Zakzanis 1998). It is also lower than the mean effect sizes for WAIS Full Scale IQs among first episode patients when compared against normal controls, $d=1.01$ (Mesholam-Gately et al. 2009). But there was no evidence of an age-related decline in IQ during the premorbid period, and there was no significant difference in the pattern of intellectual skills when considered in terms of Verbal versus Performance IQ.

As noted by the previous discussion of cognitive heterogeneity, much of the literature on premorbid cognitive deficits among persons with schizophrenia has focused on group averages, yet schizophrenia is typified by substantial interpatient heterogeneity in virtually every dimension along which this disorder may be characterized. Thus it is not at all clear that the presence of premorbid cognitive deficits typifies all persons who later develop schizophrenia. Indeed, as previously noted in the discussion of neuropsychologically normal persons with schizophrenia, there may be some persons who functioned well above average in premorbid cognitive abilities (Keefe et al. 2005; Kremen et al. 2000; Wilk et al. 2005). Also, generally consistent with theories of brain or cognitive reserve (Satz 1993; Stern 2002), it is quite possible that lower premorbid cognitive functioning, rather than reflecting the influence of genetic or other schizophrenic vulnerability, may represent a "second hit" to those genetically at risk for schizophrenia, making the phenotypic expression of that risk as clinical schizophrenia more likely (cf. Mednick and Hollister 1995).

Peri-onset cognitive changes: Data documenting the course of cognitive deficits before and after onset of clinical symptoms are relatively rare. One approach to examining this issue is to study subpopulations who received premorbid testing (such as aptitude tests administered as part of enlistment in the military), and then to re-administer the same tests at a post-onset period to people who did and who did not develop schizophrenia or other neuropsychiatric conditions. One of the earliest examples of this approach was a study by Schwartzman and Douglass (Schwartzman and Douglas 1962; Schwartzman et al. 1962), who compared the premorbid Army enlistment test scores, as well as 10-year re-test scores, of Canadian World War II veterans, including 50 who developed schizophrenia sometime after enlistment and 30 psychiatrically healthy veterans, matched to the patient group in terms of test scores at the time of enlistment. The authors found that the group that developed schizophrenia evidenced a premorbid to post-onset decline equivalent to approximately six IQ points. A detailed review of this and other early longitudinal studies is available in Heaton and Drexler (1987). 
A more recent study relevant to establishing the degree of premorbid to post-onset cognitive decline associated with schizophrenia is that of Seidman et al. (2006), who examined changes in IQ of persons with schizophrenia whose intellectual functioning had originally been assessed at age seven as part of the final visit in the National Collaborative Perinatal Project (NCPP). The latter was a prospective national study in which 50,000 people were followed periodically from the prenatal period through the first seven years of life. Seidman et al. contacted a subset of participants approximately 28 years later and readministered intelligence tests. Their report provides a longitudinal comparison of IQ test performance from age seven to an approximate 28-year follow-up among 38 people who developed schizophrenia or schizoaffective disorder and 62 non-schizophrenic controls. Consistent with findings reviewed above regarding premorbid functioning, persons who developed schizophrenia had lower IQ scores when tested as children relative to the nonschizophrenic controls; moreover, the persons with schizophrenia, on average, showed a decline of approximately 10 IQ points (adjusted for changes seen in the control group) from age seven to the time when they were re-tested in their 30 s. One interpretive caution regarding the latter finding, however, is that when comparing childhood to adult IQ scores, it can be difficult to disentangle a failure to show normative maturation/development of cognitive skills from an actual within-person decline in cognitive efficiency (Wechsler 1939).

Taken together, the admittedly limited longitudinal premorbid to postmorbid cognitive comparisons suggest that, on average, schizophrenia illness onset may be associated with one-third to one-half SD decline in general cognitive functioning.

Post-onset cognitive course: Neither the presence of premorbid cognitive deficits nor the occurrence of an initial further decline in overall cognitive functioning around the time of clinical onset of schizophrenia has generated particular controversy. There has been somewhat less consensus regarding the long-term course of cognitive deficits after onset of illness, but even in that regard, a general agreement appears to be emerging that, contrary to Kraepelin's initial suggestion that dementia praecox is characterized by a course of progressive decline, the cognitive deficits in schizophrenia tend to stabilize (Heaton et al. 2001; Kurtz 2005; Rund 1998), and may even partially improve during the initial stabilization phase immediately after first onset (Albus et al. 2002; S. Kristian Hill et al. 2004; Klingberg et al. 2008).

Longitudinal as well as cross-sectional studies of noninstitutionalized patients consistently demonstrate stable cognitive deficits after illness onset (Heaton et al. 1994,
2001; Kurtz 2005; Rund 1998). An example of the remarkable stability in neurocognitive functioning associated with schizophrenia was provided in a longitudinal study from our research group (Heaton et al. 2001) in which 142 patients with schizophrenia and 209 healthy comparison subjects were re-tested with an expanded Halstead-Reitan test battery for an average of three years (and up to 10 years). We found no evidence of cognitive decline in any of seven neurocognitive ability areas examined. Moreover, there were no differences in stability of cognitive functioning when considered in reference to shorter versus longer-term follow-up, lower versus higher baseline functioning, age of onset, elderly versus nonelderly baseline age, or when patients were categorized by stability or change in severity of positive or negative symptoms.

A possible exception to the general rule of cognitive stability in schizophrenia is the case of elderly persons who have experienced long-term institutionalization for schizophrenia (reviewed in Kurtz 2005; Rajji and Mulsant 2008; White et al. 2006). There does seem to be a greater decline in general cognitive functions than can be attributed to "normal aging" in a subgroup of such patients. This decline does not seem to be attributable to a comorbid neurodegenerative condition such as Alzheimer's disease (Friedman et al. 1999). One difficulty in interpreting such findings is that the effects of institutionalization alone are difficult to disentangle from the specific effects of schizophrenia requiring institutionalization. That said, an association between chronic institutionalization for schizophrenia and cognitive decline was observed even in some of the earliest longitudinal studies of cognitive changes in schizophrenia (e.g., Schwartzman et al. 1962). Nonetheless, as the bulk of contemporary patients with schizophrenia have not been chronically institutionalized (Cohen et al. 2000; Vahia et al. 2007), it appears that the modal pattern is one of remarkable long-term cognitive stability in the post-onset period.

\section{Neuropathology}

Precise delineation of the neuropathology underlying schizophrenia in general, or its associated neurocognitive deficits in particular, have both remained elusive despite efforts extending back over a century. There are some general patterns reviewed below.

Brain MRI studies of schizophrenia have found lower gray matter volumes (especially in the superior temporal gyrus and in medial temporal lobe and limbic structures including the amygdala, hippocampus, and parahippocampal gyrus), volume reductions in the frontal and parietal 
lobes, lack of normal asymmetries, enlargement of the caudate (perhaps related to medication), and developmental abnormalities such as presence of cavum septum pellucidum [thought to reflect aberrations in neurodevelopment; patients with larger cavum septum pellucidum may show worse performance on learning and other cognitive measures (Flashman et al. 2007)]. There are also frequent abnormalities in the size or shape of the corpus callosum (Price et al. 2007; Walterfang et al. 2008), supporting the view of schizophrenia as a disconnection syndrome (Friston and Frith 1995) and, as with earlier CT findings, there are enlarged ventricles (DeLisi 2008; Shenton et al. 2001).

Functional imaging studies have found lower activity in the prefrontal cortex and abnormal activation in the temporal lobes during performance of both verbal and visual tasks (Eyler et al. 2004, 2008; Keshavan et al. 2008). This finding is also true for PET and SPECT, where the literature suggests problems in the prefrontal and temporal regions of the brain (Lawrie et al. 2008). In resting state network studies using fMRI, results are mixed as to the effect that schizophrenia has on connectivity (Greicius 2008). Overall, the main areas that are implicated in both resting state and activation-based fMRI studies on an assortment of cognitive-based tasks include parts of the cerebral cortex (i.e., prefrontal, cingulate and temporal areas), the limbic system (specifically the hippocampus, striatum and thalamus), and the cerebellum (McGuire et al. 2008).

Additional information has come through studies employing Diffusion Tensor Imaging (DTI), which measures the fractional anisotropy of white matter tracts (i.e., how intact the tracts are). In schizophrenia, rather consistent findings are abnormalities in these tracts, leading to increased diffusivity in the prefrontal and temporal lobes, corpus callosum, uncinate fascicules, cingulum bundle, and arcuate fasciculus (Assaf and Pasternak 2008; Kubicki et al. 2007). The white matter findings of Wexler et al. (2009), described above in the section on neuropsychologically normal schizophrenia, suggested abnormalities of functional connectivity in participants with schizophrenia and cognitive impairment, but not in healthy controls or participants with schizophrenia and no cognitive impairment.

Other significant central nervous system findings in schizophrenia are in neurochemical dysfunction (e.g., reduced $\mathrm{N}$-acetyl aspartate in the frontal and temporal lobes, hypercortisolemia and hypothalamo-pituitary-adrenal axis dysregulation, and an increase in D2 receptors in the striatum), neurophysiological dysfunction (including abnormal prepulse inhibition, decreased P300 amplitudes, and REM sleep abnormalities), and at autopsy, decreased dendritic density accompanied by normal or increased neuron density and an absence of gliosis (Keshavan et al. 2008).

\section{Effects on Everyday Functioning}

There has been long-standing interest in the functional importance of neurocognitive deficits in schizophrenia. More than 30 years ago, the senior author of the present review (RKH) noted "The clinical value of neuropsychological evaluation would be increased considerably if it could also provide some reliable information regarding the patient's abilities to meet the demands of his [or her] everyday life" (Heaton 1976, p. 11). A wealth of empirical research relevant to establishing such clinical value in multiple clinical and nonclinical populations has arisen in the subsequent three and a half decades (Green 1996; Green et al. 2000; Heaton and Pendleton 1981; Kurtz 2006). In particular, the empirical literature is quite clear and consistent in demonstrating that, whereas the positive symptoms of schizophrenia have little or no demonstrable effect on everyday functioning, the neurocognitive deficits, and to lesser degree negative symptoms, are significant correlates of functional capacity, and (perhaps less directly) levels of manifest everyday functioning.

The issue of whether there are differential effects of impairment in specific cognitive domains on overall functional capacity or status is less clear. In Green's (1996) classic review of this literature, he divided the types of functional capacity, status, or outcome variables into three categories: (a) independence in community functioning, (b) social problem solving, and (c) skill acquisition. The strongest evidence for significant cognitive correlates was with tests of auditory episodic memory (which Green labeled "secondary verbal memory"), for which at least some studies found significant correlations with community functioning, social problem solving, and skill acquisition. The evidence regarding an association with executive functions (as assessed with Wisconsin Card Sorting Test [WCST]) was strong for community functioning, weaker for skill acquisition, and non-significant for social problem solving. The evidence for vigilance (as measured with a Continuous Performance Test) was strong for social problem solving and skill acquisition, but absent (not assessed) for community functioning. Green concluded that auditory memory and vigilance appear to be necessary for adequate functional outcome.

One might be tempted to interpret these reviewed findings as indicative of differential importance of specific cognitive dimensions, but Green (1996) himself was careful to note that his conclusions were limited by the infrequency with which specific associations had actually been assessed and reported in the empirical literature. Moreover, in a subsequent updated review of the literature, Green et al. (2000) found that the largest amount of variance (between 20 and 60 percent) in functional outcome was predicted by global or composite cognitive (rather than domain-specific) measures of neurocognition. This is not surprising because, 
as discussed above, schizophrenia is typically associated with multiple deficits in varying patterns, rather than with any single isolated cognitive impairment. In addition, with the larger number of studies available in the 2000 review, Green et al. (2000) found further evidence that the strength of documented associations may be influenced by the frequency with which the associations have been examined in the literature. For example, the updated review found studies in which executive functions (WCST scores) were associated with social problem solving, in addition to skill acquisition and community functioning.

Results of several studies from our research group and others suggest that the association between cognitive deficits and impairments in functional capacity or status are generally non-specific (Evans et al. 2003; Palmer et al. 2002; Palmer and Jeste 2006; Twamley et al. 2002; Velligan et al. 2000). Such findings do not necessarily mean that there are no differential relationships between specific cognitive deficits and specific functional tasks. However, efforts to unequivocally document the presence and nature of such relationships are hampered by the multi-factorial nature of standard neurocognitive tests (Dickinson and Gold 2008; Gladsjo et al. 2004; The Psychological Corporation 1997), the multifactorial nature of most everyday tasks and activities, the lack of neurocognitive (as well as functional outcome) tests of different domains that have documented psychometric equivalence (Chapman and Chapman 1973), the above mentioned heterogeneity of cognitive profiles of schizophrenia, and differences in opportunity of patients to perform certain everyday tasks and activities (Bellack et al. 2007).

The last decade also brought increased interest in the degree to which the association between the cognitive deficits and functional disability associated with schizophrenia might be exceeded or partially mediated by deficits in what has been called "social cognition" (Green et al. 2000; Green and Leitman 2008; Kee et al. 1998), a term which in the context of schizophrenia research has been defined as referring to the following constructs: theory of mind (requiring inferences about the mental states of others), social perception, social knowledge, attributional biases, and emotional processing (see Green et al. 2008). [It should be noted that such use of the term "social cognition" is narrower than originally developed within the field of social psychology, wherein it includes a broader array of constructs such as perceived self-efficacy, outcome expectancies, and perceived locus of control (e.g., Bandura 1986; Mischel 1973; Rotter 1966)]. Accumulating evidence supports the contention that persons with schizophrenia, and even first-degree relatives, may show deficits in at least some of these social cognitive dimensions (Bora et al. 2009; Eack et al. 2009; Marwick and Hall 2008), and that they do indeed affect functional outcome (Couture et al.
2006). Research is ongoing, but the body of published research in which identical constructs have been examined is presently too small to draw firm conclusions regarding the degree to which social cognitive deficits supplement, supplant, or mediate the effects of "generic" neurocognition on everyday function (Bowie et al. 2008; Pijnenborg et al. 2009; Vauth et al. 2004). It appears likely that some of the effects of cognition on outcome will be mediated through social cognitive abilities, but that not all aspects of everyday functioning depend on social efficiency or skill.

\section{Treatment}

Pharmacologic: The era of conventional neuroleptics began when the antipsychotic properties of chlorpromazine were first identified in France in 1952; chlorpromazine received FDA approval two years later in March 1954 (Crilly 2007). Although chlorpromazine and other subsequently developed neuroleptic medications were eventually found to have serious potential side-effects such as tardive dyskenisia (reviewed in Jeste et al. 1999), they were generally thought to have minimal effects on cognition (either positive or deleterious), with the possible exception of partial normalization of some aspects of attention (e.g., Cassens et al. 1990; Spohn and Strauss 1989). However, Mishara and Goldberg (2004) noted that this "general wisdom" about the lack of beneficial effects of conventional neuroleptic medications on cognitive deficits in schizophrenia was based exclusively on narrative reviews of the empirical literature, i.e., there was no extant quantitative/meta-analytic review. The latter authors conducted a meta-analyses of the available empirical literature and found, contrary to conventional wisdom, that that there might indeed be some beneficial neurocognitive effects of conventional neuroleptic medications which, while modest in size (mean effect size $d=0.22$ ), at least warrant further empirical inquiry (Mishara and Goldberg 2004).

The era of "atypical" or "second generation" antipsychotic medications is a long and circuitous one dating back to the late 1950s (Crilly 2007; Hippius 1999), but systematic study of the effects of second generation antipsychotic medications on the neuropsychological deficits in schizophrenia began in the early to mid-1990s. The subsequent decade brought some suggestions that second generation antipsychotic medications might partially improve certain aspects of neurocognitive functioning (Harvey and Keefe 2001; Keefe et al. 1999; Meltzer and McGurk 1999; Woodward et al. 2005). However, whether atypical antipsychotic medications actually produce functionally relevant degrees of cognitive benefit remains a point of debate (Carpenter and Gold 2002). 
The largest and most comprehensive investigation of the cognitive effects of antipsychotic medications was provided by the NIMH-sponsored Clinical Antipsychotic Trials of Intervention Effectiveness (CATIE) schizophrenia study (Keefe et al. 2007). The CATIE study involved a randomized double-blind comparison of schizophrenia treatment for up to 18 months with any of five medications, including four second generation antipsychotics (olanzapine, quetiapine, risperidone, or ziprasidone) and one conventional neuroleptic (perphenazine). The cognitive effectiveness analyses were based on 817 patients who completed at least a baseline and 2month follow-up assessments. There was a significant improvement in overall cognitive performance within each of the treatment groups, and there were no significant differences between the treatment groups in terms of changes in any of five specific cognitive domains. Similar findings were seen in the subset of participants for whom 6- or 18month follow-up data were available. The difference in cognitive scores from 2- to 18-months was negligible, suggesting the bulk of improvement occurred in the first two months of treatment. Overall changes in each of the groups, while statistically significant, were small and of questionable functional importance, and given the absence of an untreated group, could at least partially reflect practice effects. If anything, however, participants randomized to the conventional neuroleptic manifested greater improvement in cognitive performance than did those randomized to second generation antipsychotics. Specifically, exploratory pairwise comparisons of 18-month change scores suggested that improvement in the neurocognitive composite score was better in the group randomized to treatment with the conventional neuroleptic (perphenazine) relative to those randomized to treatment with olanzapine or risperidone.

One important interpretive caveat mentioned by Keefe et al. (2007) was that the majority of patients in the CATIE study were already receiving treatment with one or more antipsychotic medications at the time of study entry. The overall pattern of results did not change even when the investigators adjusted the analyses to account for patients' reports of their baseline antipsychotic medication; nonetheless, the possibility cannot be ruled out that acute cognitive benefits of second generation antipsychotic medications may have been attenuated by prior treatment with the same medication. Even so, such experience would not explain the (unexpected) finding of cognitive benefits from the conventional neuroleptic, perphenazine. The findings from more recent report from the European First Episode Schizophrenia Trial also suggest no differential cognitive benefit of second generation antipsychotics versus conventional neuroleptics (Davidson et al. 2009). In the latter study, 498 first episode schizophrenia patients (each with less than 2 weeks exposure to antipsychotic medications in the year preceding study enrollment) were randomly assigned to treatment with a conventional neuroleptic (haloperidol) or one of four second generation antipsychotic medications (amisulpride, olanzapine, quetiapine, or ziprasidone). Comparison of baseline to 6-month follow-up assessments indicated statistically significant improvements in overall cognitive test performance, but there were no differences in the magnitude of the changes among the five medication groups.

The question of differential cognitive benefits of second generation versus conventional neuroleptic medications is not fully settled (Woodward et al. 2005, 2007). In light the documented effect sizes, however, there appears little reason to be very enthusiastic about the cognitive benefits of either class of medication. On the other hand, this conclusion relates only to the potential cognitive effects of medications intended primarily to treat the psychotic symptoms. Efforts to develop more targeted pharmacologic treatments for cognition in schizophrenia are represented by the NIMHsponsored Measurement and Treatment Research to Improve Cognition in Schizophrenia (MATRICS), Treatment Units for Research on Neurocognition and Schizophrenia (TURNS), and Cognitive Neuroscience Treatment Research to Improve Cognition in Schizophrenia (CNTRICS) projects (Buchanan et al. 2007; Carter et al. 2008; Green 2007; Marder 2006). Although development of drugs targeting cognitive deficits in schizophrenia remains in the early stages, these initiatives represent an important step forward toward identification and development of promising compounds or targets, to be tested by systematic efficacy and effectiveness trials, and hopefully culminating in eventual regulatory approval of safe and effective medications for this key component of the illness.

Cognitive rehabilitation: In recent years, there has been an increasing recognition of the need for psychosocial rehabilitative interventions for schizophrenia (Insel 2009). In that regard, recent efforts to develop cognitive training programs for schizophrenia offer promise (Twamley et al. 2003; Velligan et al. 2006). In general, these interventions tend to be most effective when focused on teaching patients compensatory strategies (i.e., to help patients identify ways of minimizing the deleterious influence of cognitive deficits, and to draw upon any cognitive or environmental strengths that may be available). For example, Elizabeth Twamley, with other colleagues in our research group, recently developed a manualized 12 -week cognitive rehabilitation program focused on teaching of compensatory strategies and habit learning, and pilot tested its efficacy (relative to pharmacotherapy alone) through a randomized controlled trial (Twamley et al. 2008). At the post-treatment assessment, those in the cognitive training group reported fewer cognitive problems and more use of compensatory strategies than those in the pharmacotherapy-alone group. Replication and refinement is needed, but this study 
illustrates the importance and viability of looking beyond pharmacologic interventions to address the functional effects of neurocognitive deficits in schizophrenia. (Please see Medalia and Choi (2009), this volume, for a comprehensive review of cognitive remediation in schizophrenia.)

\section{Summary and Conclusions}

Application of a neuropsychological perspective to the study of schizophrenia has established a number of important facts about this disorder. Some of the highlights and key conclusions that can be drawn from our review of this literature are summarized in Table 1, top among which are that there is (a) substantial interpatient heterogeneity in cognitive function, (b) remarkable cognitive stability over the course of the illness, and (c) that severity of cognitive deficits, not psychopathologic symptoms, seems to be the primary determinant of impairments functional capacity and functional status. The heterogeneity in cognitive functioning provides tangible reason to express hope to patients and their families that schizophrenia is by no means typically accompanied by profound cognitive deficits or by a lifelong progressive decline in functioning. Thus contemporary data provide a substantially more optimistic picture than that portrayed by the classic Kraeplinian notion of schizophrenia as a dementia praecox. Recognition of the functional effects of cognitive deficits has been important in directing treatment development efforts away from the previous exclusive focus on reduction or management of psychotic symptoms, and toward a broader consideration of the need for interventions that beneficially influence effects of the cognitive deficits and negative symptoms that may be more important determinants of residual disability.

One other tangible benefit of this body of research is that it further establishes the view of schizophrenia as a neurobiologic disorder. Although neurobiologic models of schizophrenia date back to its earliest conceptualization, the 20th century also witnessed periods in which purely psychogenic models dominated the field. The latter models sometimes had the inadvertent effect of reinforcing the stigma experienced by patients with this disorder and their families. For instance, the "schizophrenogenic mother" theory was a particularly notorious psychogenic model that often contributed to unwarranted guilt among family members about the affected person's condition (reviewed in Hartwell 1996).

Where should the field go from here? One consistent issue that strikes us is the difficulty in firmly establishing the presence of differential cognitive deficits in terms of specific cognitive domains or patterns. As noted in our introductory comments, one of the key motivating factors or assumptions behind much of the contemporary neuropsychological research in schizophrenia has been the hope/assumption that specification of the neurocognitive pattern(s) associated with schizophrenia may help clarify the neuroanatomic and/or neurophysiologic regions or systems that underlie expression of this disorder (Levin et al. 1989). While the data seem to point to some degree to temporal and frontal-subcortical brain systems, these were among the regions Kraepelin (1971/1919/1913) himself expressed interest in almost a century ago, and which were reiterated by others, such as in the previously cited quote from Kurt Goldstein in 1939 (Goldstein 1939). Judged from that perspective, the degree of progress is unimpressive.

Closely related to the difficulty in establishing differential cognitive deficits characterizing schizophrenia is the question of specificity. That is, given that one of the reasons to consider the pattern(s) of neuropsychological strengths and weaknesses associated with schizophrenia is to understand the underlying neurobiology associated with manifestation of the clinical syndrome, it would be helpful to discern the degree to which the level and pattern(s) of neurocognitive deficits associated with schizophrenia are distinct from those of other forms of serious mental illness, such as schizoaffective disorder or bipolar disorder. With a few isolated exceptions, most studies comparing level, pattern, and frequency of neurocognitive deficits among patients with schizophrenia versus schizoaffective disorder suggest no reliable differences (reviewed in Palmer and Savla 2009). [Recent reports on preparation of the DSM-V, scheduled for publication in 2012, indicate plans to eliminate schizoaffective disorder as diagnostic entity separate from schizophrenia (Gever 2009).] Comparisons of persons with schizophrenia to those with bipolar disorder have led to a more complex pattern of results. In an interesting contrast to schizophrenia, in which duration of illness, symptom severity, and fluctuations of symptoms do not substantially influence severity of cognitive deficits (Heaton et al. 1994, 2001; Nayak et al. 2006; Palmer et al. 1997), a number of studies suggest that some cognitive functions are adversely affected by severity of current manic or depressive symptoms in bipolar patients (reviewed in Goldberg and Burdick (2008)). However, cognitive deficits are also present during the inter-episode periods of relative remission/euthymia among many persons with bipolar disorder (Cavanagh et al. 2002; Martinez-Aran et al. 2004a, b; Torrent et al. 2006). These deficits may be worse among patients with a longer duration of illness and with higher numbers of lifetime affective episodes (Bearden et al. 2001; Cavanagh et al. 2002; Denicoff et al. 1999; El-Badri et al. 2001; Lebowitz et al. 2001; Zubieta et al. 2001). Yet, the primary finding in comparison of neuropsychological profiles among persons with schizophrenia versus bipolar disorder is that those with bipolar disorder tend to have a similar profiles of impairment, but have a 
Table 1 Summary of key findings from the empirical literature on neuropsychological aspects of schizophrenia

\begin{tabular}{ll}
\hline Domain of inquiry & Key findings \\
\hline Level of impairment & Heterogeneous findings between persons, between domains, and between studies, but on average, schizophrenia is \\
& associated with a mild-to-moderate degree of cognitive deficit approximately one standard deviation below the \\
& normative mean \\
& Generalized impairment in most cognitive domains; some evidence of stronger effect sizes for aspects of immediate \\
& recall on episodic declarative memory tasks, and for processing speed, with lower (but still medium to large) effect \\
Pattern & sizes in reference to crystallized knowledge and visual-spatial skills. There is little consistent evidence of \\
& differential decline in working memory or executive functions, despite long-standing interest in these domains as \\
& potential core deficits in schizophrenia.
\end{tabular}

Heterogeneity

About $20 \%$ to $25 \%$ of patients with schizophrenia retain a psychometrically normal pattern of neurocognitive functions. Neuropsychologically normal status does not appear to represent differences in severity of illness, as reflected by psychotic symptoms. Cluster analytic studies also suggest the presence of a severely impaired subgroup, which would be consistent with earlier notions of deficit syndrome, Type II, and/or negative symptom schizophrenia.

Course

Mild (on average) premorbid cognitive deficits; further decline at the time of onset of clinical symptoms equivalent to about 5 to 10 IQ points (with partial recovery of cognitive functions during the stabilization phase after first onset); a stable pattern of cognitive functions across all neurocognitive domains over the long-term chronic course among non-institutionalized patients

Neuropathology Precise delineation of the neuropathology underlying schizophrenia in general, or its associated neurocognitive deficits in particular, has remained elusive despite efforts extending back over a century. However, general patterns include decreased gray matter volume (particularly in the temporal and limbic structures), as well as enlarged caudate and ventricles. Functional imaging studies suggest decreased activity in the prefrontal cortex and abnormal activation in the temporal lobes during both verbal and visual tasks. Diffusion Tensor Imaging (DTI) studies suggest schizophrenia may be associated with increased diffusivity, in the prefrontal and temporal lobes, corpus callosum, uncinate fascicules, cingulum bundle and arcuate fasciculus.

Effects on everyday functioning

Positive symptoms of schizophrenia have little effect on everyday functioning. Neurocognitive deficits, and to lesser degree negative symptoms, are significant correlates functional capacity, and to a lesser degree levels of manifest everyday functioning. Little compelling evidence of differential associations between specific cognitive deficits and impairments in specific dimensions of functional capacity or status. Whether and the degree to which, or under what specific conditions, the association between cognitive deficits and deficits in everyday functioning are supplemented by, supplanted by, or mediated by the effects on social competence related skills ("social cognition") remains an open question.

Amenability to treatment Relative cognitive benefits of conventional versus second generation antipsychotic medications remains a point of unresolved debate, but none has been shown to result in substantial (functionally relevant) levels of cognitive improvement. Efforts are ongoing to develop pharmacologic agents that would directly target the cognitive deficits associated with schizophrenia, as well as to develop and validate non-pharmacologic cognitive compensatory programs.

less severe degree of impairment (Depp et al. 2007; Schretlen et al. 2007; Seidman et al. 2002).

Much of the existing research on cognitive deficits in schizophrenia also was motivated by a general presumption that identifying cognitive strengths and weaknesses within persons with schizophrenia, and the relationship of such cognitive abilities/deficits to psychosocial or independent functions, would have clinical value in developing effective placement and rehabilitation plans. While the relationship between cognitive function in general and functional capacity is firmly established, the evidence for differential relationships between specific cognitive dimensions and specific tasks or demands of everyday living remains murky.

In part, the difficulties in making greater progress in establishing the presence of differential cognitive deficits and differential relationships with specific aspects of everyday functioning may reflect the heterogeneous nature of schizophrenia. Eugen Bleuler (1950/1911) appears to have been wise in describing the disorder with the plural ("schizophrenias") rather than singular ("schizophrenia") form. It is possible that further advances in neuroimaging, genomics, and epigenetics will help identify more homogenous neurocognitive subtypes than are presently available. Also, Kremen et al. (2000) noted that "examination of individual neuropsychological profiles could be a useful alternative to group analysis for making sense of heterogeneity in schizophrenia" (p. 744). One patient may evidence difficulty on a list learning task due to impairments in memory consolidation associated with medial temporal lobe dysfunction, whereas another patient's poor performance on that same task may reflect deficits in frontal or frontal-subcortical systems related executive functions, e.g., resulting in choice and application of a suboptimal encoding strategy. In recognition of such possibilities, in clinical interpretation, neuropsychologists do not typically or automatically interpret tests as measures of their named or standard cognitive constructs, but rather attempt to come up with hypotheses of the latent deficit(s) that may explain 
the pattern of strengths and weaknesses across a set of tests. Yet in neurocognitive research there is a tendency to equate deficits on specific test scores with their labeled ability. The apparent diffuse or nonspecific nature that seems to best characterize the "average" pattern of neurocognitive deficits in schizophrenia may, at least in part, reflect the fact that we (as a field) tend to blend "apples and oranges" and then try to say something intelligent about "average" fruit. Further advances in analytic methodology may enable researchers to more effectively apply process or idiographic interpretation to large sets of cognitive data from schizophrenia patients and their subgroups (cf. Barlow and Nock 2009).

In addition, there remains a need for better neurocognitive measures that are more sensitive and specific to deficits in discrete cognitive functions. Many of the commonly used cognitive measures have shown relatively little modification from their original forms over the past 50 to 100 years (Berg 1948; Boake 2000, 2002; MacLeod 1991; Partington and Leiter 1949; Wechsler 1939). These are all well-established tools, and remain valued components of the neuropsychological armory, but it must also be recognized that they were generally developed and designed for uses quite distinct from establishing differential cognitive deficits in neuropsychiatric conditions. There is reason for optimism that the tide is turning in this regard. In particular, the Cognitive Neuroscience Treatment Research to Improve Cognition in Schizophrenia (CNTRICS) initiative is a recent cognitive neuroscience focused spin-off of the more widely known, clinically construct-oriented MATRICS project (Carter et al. 2008). The aim of the CNTRICS is to identify promising constructs from cognitive neuroscience which may be useful in identifying more specific or elementary cognitive processes related to more specific brain systems involved in schizophrenia. Whether the products of this initiative will in fact lead to more sensitive and specific measures of differential cognitive abilities/deficits in schizophrenia is uncertain, but it seems a timely and worthy attempt.

Acknowledgments This work was supported, in part, by National Institute of Mental Health grants P30 MH080002, T32 MH019934, and R01MH064722.

Disclosures The authors have no conflicts of interest to report.

Open Access This article is distributed under the terms of the Creative Commons Attribution Noncommercial License which permits any noncommercial use, distribution, and reproduction in any medium, provided the original author(s) and source are credited.

\section{References}

Albus, M., Hubmann, W., Scherer, J., Dreikorn, B., Hecht, S., Sobizack, N., et al. (2002). A prospective 2-year follow-up study of neurocognitive functioning in patients with first-episode schizophrenia. European Archives of Psychiatry and Clinical Neuroscience, 252(6), 262-267.

Aleman, A., Hijman, R., de Haan, E. H., \& Kahn, R. S. (1999). Memory impairment in schizophrenia: a meta-analysis. American Journal of Psychiatry, 156(9), 1358-1366.

Allen, D. N., Goldstein, G., \& Warnick, E. (2003). A consideration of neuropsychologically normal schizophrenia. Journal of the International Neuropsychological Society, 9(1), 56-63.

Allen, D. N., Huegel, S. G., Seaton, B. E., Goldstein, G., Gurklis, J. A., Jr., \& van Kammen, D. P. (1998). Confirmatory factor analysis of the WAIS-R in patients with schizophrenia. Schizophrenia Research, 34(1-2), 87-94.

Allen, D. N., Seaton, B. E., Goldstein, G., Sanders, R. D., Gurklis, J. A., Jr., Peters, J. L., et al. (2000). Neuroanatomic differences among cognitive and symptom subtypes of schizophrenia. Journal of Nervous and Mental Disease, 188 (6), 381-384.

Assaf, Y., \& Pasternak, O. (2008). Diffusion tensor imaging (DTI)based white matter mapping in brain research: a review. Journal of Molecular Neuroscience, 34(1), 51-61.

Aylward, E., Walker, E., \& Bettes, B. (1984). Intelligence in schizophrenia: meta-analysis of the research. Schizophrenia Bulletin, 10(3), 430-459.

Babcock, H. (1933). Dementia praecox: A psychological study. Oxford: Science.

Bandura, A. (1986). Social foundations of thought and action: a social cognitive theory. Englewood Cliffs: Prentice-Hall, Inc.

Barlow, D. H., \& Nock, M. K. (2009). Why can't we be more idiographic in our research? Perspectives on Psychological Science, 4(1), 19-21.

Bearden, C. E., Hoffman, K. M., \& Cannon, T. D. (2001). The neuropsychology and neuroanatomy of bipolar affective disorder: a critical review. Bipolar Disorders, 3(3), 106-150. discussion 151-103.

Bellack, A. S., Green, M. F., Cook, J. A., Fenton, W., Harvey, P. D., Heaton, R. K., et al. (2007). Assessment of community functioning in people with schizophrenia and other severe mental illnesses: a white paper based on an NIMH-sponsored workshop. Schizophrenia Bulletin, 33(3), 805-822.

Berg, E. A. (1948). A simple objective technique for measuring flexibility in thinking. Journal of General Psychology, 39, 15-22.

Bilder, R. M., Reiter, G., Bates, J., Lencz, T., Szeszko, P., Goldman, R. S., et al. (2006). Cognitive development in schizophrenia: follow-back from the first episode. Journal of Clinical and Experimental Neuropsychology, 28(2), 270-282.

Bleuler, E. P. (1930). The physiogenic and psychogenic in schizophrenia. American Journal of Psychiatry, 10(2), 203-211.

Bleuler, E. (1950/1911). Dementia praecox; or the group of schizophrenias (J. Zinkin, Trans.). New York: International Universities Press.

Boake, C. (2000). Édouard Claparède and the auditory verbal learning test. Journal of Clinical and Experimental Neuropsychology, 22 (2), 286-292.

Boake, C. (2002). From the Binet-Simon to the Wechsler-Bellevue: tracing the history of intelligence testing. Journal of Clinical and Experimental Neuropsychology, 24(3), 383-405.

Bolles, M., \& Goldstein, K. (1938). A study of the impairment of "abstract behavior" in schizophrenic patients. Psychiatric Quarterly, 12, 42-65.

Bora, E., Yucel, M., \& Pantelis, C. (2009). Theory of mind impairment in schizophrenia: meta-analysis. Schizophrenia Research, 109(1-3), 1-9.

Bowie, C. R., Leung, W. W., Reichenberg, A., McClure, M. M., Patterson, T. L., Heaton, R. K., et al. (2008). Predicting schizophrenia patients' real-world behavior with specific neuro- 
psychological and functional capacity measures. Biological Psychiatry, 63(5), 505-511.

Braff, D. L., Heaton, R. K., Kuck, J., Cullum, M., Moranville, J., Grant, I., et al. (1991). The generalized pattern of neuropsychological deficits in outpatients with chronic schizophrenia with heterogeneous Wisconsin Card Sorting Test results. Archives of General Psychiatry, 48(10), 891-898.

Bryson, G. J., Silverstein, M. L., Nathan, A., \& Stephen, L. (1993). Differential rate of neuropsychological dysfunction in psychiatric disorders: comparison between the Halstead-Reitan and LuriaNebraska batteries. Perceptual and Motor Skills, 76(1), 305-306.

Buchanan, R. W., Freedman, R., Javitt, D. C., Abi-Dargham, A., \& Lieberman, J. A. (2007). Recent advances in the development of novel pharmacological agents for the treatment of cognitive impairments in schizophrenia. Schizophrenia Bulletin, 33(5), $1120-1130$.

Cameron, N. (1939a). Deterioration and regression in schizophrenic thinking. The Journal of Abnormal and Social Psychology, 34(2), 265-270.

Cameron, N. (1939b). Schizophrenic thinking in a problem-solving situation. Journal of Mental Science, 85, 1012-1035.

Carpenter, W. T., \& Gold, J. M. (2002). Another view of therapy for cognition in schizophrenia. Biological Psychiatry, 51(12), 969-971.

Carter, C. S., Barch, D. M., Buchanan, R. W., Bullmore, E., Krystal, J. H., Cohen, J., et al. (2008). Identifying cognitive mechanisms targeted for treatment development in schizophrenia: an overview of the first meeting of the cognitive neuroscience treatment research to improve cognition in schizophrenia initiative. Biological Psychiatry, 64(1), 4-10.

Cassens, G., Inglis, A. K., Appelbaum, P. S., \& Gutheil, T. G. (1990). Neuroleptics: effects on neuropsychological function in chronic schizophrenic patients. Schizophrenia Bulletin, 16(3), 477-499.

Cavanagh, J. T., Van Beck, M., Muir, W., \& Blackwood, D. H. (2002). Case-control study of neurocognitive function in euthymic patients with bipolar disorder: an association with mania. British Journal of Psychiatry, 180, 320-326.

Chapman, L. J., \& Chapman, J. P. (1973). Problems in the measurement of cognitive deficit. Psychological Bulletin, 79(6), 380-385.

Cohen, J. (1988). Statistical power analysis for the behavioral sciences. Hillsdale: Lawrence Erlbaum Associates, Inc.

Cohen, C. I., Cohen, G. D., Blank, K., Gaitz, C., Katz, I. R., Leuchter, A., et al. (2000). Schizophrenia and older adults: an overview: directions for research and policy. American Journal of Geriatric Psychiatry, 8(1), 19-28.

Couture, S. M., Penn, D. L., \& Roberts, D. L. (2006). The functional significance of social cognition in schizophrenia: a review. Schizophrenia Bulletin, 32(suppl_1), S44-63.

Crilly, J. (2007). The history of clozapine and its emergence in the US market: a review and analysis. History of Psychiatry, 18(1), 39-60.

Davidson, M., Galderisi, S., Weiser, M., Werbeloff, N., Fleischhacker, W. W., Keefe, R. S., et al. (2009). Cognitive effects of antipsychotic drugs in first-episode schizophrenia and schizophreniform disorder: a randomized, open-label clinical trial (EUFEST). American Journal of Psychiatry, 166(6), 675-682.

de Gracia Dominguez, M., Viechtbauer, W., Simons, C. J., van Os, J., \& Krabbendam, L. (2009). Are psychotic psychopathology and neurocognition orthogonal? A systematic review of their associations. Psychological Bulletin, 135(1), 157-171.

DeLisi, L. (2008). The concept of progressive brain change in schizophrenia: implications for understanding schizophrenia. Schizophrenia Bulletin, 34(2), 312-321.

Denicoff, K. D., Ali, S. O., \& Mirsky, A. F. (1999). Relationship between prior course of illness and neuropsychological functioning in patients with bipolar disorder. Journal of Affective Disorders, 56, 67-73.
Depp, C. A., Moore, D. J., Sitzer, D., Palmer, B. W., Eyler, L. T., Roesch, S., et al. (2007). Neurocognitive impairment in middleaged and older adults with bipolar disorder: comparison to schizophrenia and normal comparison subjects. Journal of Affective Disorders, 101(1-3), 201-209.

Dickinson, D., \& Gold, J. M. (2008). Less unique variance than meets the eye: overlap among traditional neuropsychological dimensions in schizophrenia. Schizophrenia Bulletin, 34(3), 423-434.

Dickinson, D., Ramsey, M. E., \& Gold, J. M. (2007). Overlooking the obvious: aameta-analytic comparison of digit symbol coding tasks and other cognitive measures in schizophrenia. Archives of General Psychiatry, 64(5), 532-542.

Eack, S. M., Montrose, D. M., Mermon, D. E., Miewald, J., Gur, R. E., Gur, R. C., et al. (2009). Social cognition deficits among individuals at familial high risk for schizophrenia. Schizophrenia Bulletin.

El-Badri, S. M., Ashton, C. H., Moore, P. B., Marsh, V. R., \& Ferrier, I. N. (2001). Electrophysiological and cognitive function in young euthymic patients with bipolar affective disorder. Bipolar Disorders, 3(2), 79-87.

Evans, J. D., Heaton, R. K., Paulsen, J. S., Palmer, B. W., Patterson, T., \& Jeste, D. V. (2003). The relationship of neuropsychological abilities to specific domains of functional capacity in older schizophrenia patients. Biological Psychiatry, 53(5), 422-430.

Eyler, L. T., Jeste, D. V., \& Brown, G. G. (2008). Brain response abnormalities during verbal learning among patients with schizophrenia. Psychiatry Research, 162(1), 11-25.

Eyler, L. T., Olsen, R. K., Jeste, D. V., \& Brown, G. G. (2004). Abnormal brain response of chronic schizophrenia patients despite normal performance during a visual vigilance task. Psychiatry Research, 130(3), 245-257.

Fey, E. T. (1951). The performance of young schizophrenics and young normals on the Wisconsin Card Sorting Test. Journal of Consulting Psychology, 15(4), 311-319.

Fioravanti, M., Carlone, O., Vitale, B., Cinti, M. E., \& Clare, L. (2005). A meta-analysis of cognitive deficits in adults with a diagnosis of schizophrenia. Neuropsychology Review, 15(2), 73-95.

Flashman, L. A., Roth, R. M., Pixley, H. S., Cleavinger, H. B., McAllister, T. W., Vidaver, R., et al. (2007). Cavum septum pellucidum in schizophrenia: clinical and neuropsychological correlates. Psychiatry Research: Neuroimaging, 154(2), 147-155.

Friedman, J. I., Harvey, P. D., Kemether, E., Byne, W., \& Davis, K. L. (1999). Cognitive and functional changes with aging in schizophrenia. Biological Psychiatry, 46(7), 921-928.

Friston, K. J., \& Frith, C. D. (1995). Schizophrenia: a disconnection syndrome? Clinical Neuroscience, 3(2), 89-97.

Gever, J. (2009). APA: Major changes loom for bible of mental health. Medpage Today Retrieved June 12, 2009, from http://www. medpagetoday.com/MeetingCoverage/APA/14270

Gladsjo, J. A., McAdams, L. A., Palmer, B. W., Moore, D. J., Jeste, D. V., \& Heaton, R. K. (2004). A six-factor model of cognition in schizophrenia and related psychotic disorders: relationships with clinical symptoms and functional capacity. Schizophrenia Bulletin, 30(4), 739-754.

Goldberg, J. F., \& Burdick, K. E. (eds). (2008). Cognitive dysfunction in bipolar disorder: A guide for clinicians. Washington DC: American Psychiatric Press, Inc.

Goldberg, T. E., Ragland, J. D., Torrey, E. F., Gold, J. M., Bigelow, L. B., \& Weinberger, D. R. (1990). Neuropsychological assessment of monozygotic twins discordant for schizophrenia. Archives of General Psychiatry, 47(11), 1066-1072.

Goldman-Rakic, P. S. (1994). Working memory dysfunction in schizophrenia. Journal of Neuropsychiatry and Clinical Neurosciences, 6(4), 348-357.

Goldstein, K. (1939). The significance of special mental tests for diagnosis and prognosis in schizophrenia. American Journal of Psychiatry, 96(3), 575-588. 
Goldstein, K. (1949). Frontal lobotomy and impairment of abstract attitude. Journal of Nervous and Mental Disease, 110, 93-111.

Goldstein, K. (1959). Concerning the concreteness in schizophrenia. The Journal of Abnormal and Social Psychology, 59(1), 146-148.

Goldstein, G. (1990a). Contributions of Kurt Goldstein to neuropsychology. The Clinical Neuropsychologist, 4(1), 3-17.

Goldstein, G. (1990b). Neuropsychological heterogeneity in schizophrenia: a consideration of abstraction and problem-solving abilities. Archives of Clinical Neuropsychology, 5(3), 251-264.

Goldstein, G. (2009). Neuropsychology in New York City (1930 1960). Archives of Clinical Neuropsychology, 24(2), 137-143.

Goldstein, G., Allen, D. N., \& Seaton, B. E. (1998). A comparison of clustering solutions for cognitive heterogeneity in schizophrenia. Journal of the International Neuropsychological Society, 4(4), $353-362$.

Goldstein, K., \& Scheerer, M. (1941). Abstract and concrete behavior: an experimental study with special tests. Psychological Monographs, 53(2), 151.

Green, M. F. (1996). What are the functional consequences of neurocognitive deficits in schizophrenia? American Journal of Psychiatry, 153(3), 321-330.

Green, M. F. (2007). Stimulating the development of drug treatments to improve cognition in schizophrenia. Annual Review of Clinical Psychology, 3, 159-180.

Green, M. F., Kern, R. S., Braff, D. L., \& Mintz, J. (2000). Neurocognitive deficits and functional outcome in schizophrenia: are we measuring the "right stuff"? Schizophrenia Bulletin, 26(1), 119-136.

Green, M. F., \& Leitman, D. I. (2008). Social cognition in schizophrenia. Schizophrenia Bulletin, 34(4), 670-672.

Green, M. F., Penn, D. L., Bentall, R., Carpenter, W. T., Gaebel, W., Gur, R. C., et al. (2008). Social cognition in schizophrenia: an NIMH workshop on definitions, assessment, and research opportunities. Schizophrenia Bulletin, 34(6), 1211-1220.

Greicius, M. (2008). Resting-state functional connectivity in neuropsychiatric disorders. Current Opinion in Neurology, 21(4), 424-430.

Harrison, P. J. (2004). The hippocampus in schizophrenia: a review of the neuropathological evidence and its pathophysiological implications. Psychopharmacology, 174(1), 151-162.

Harrison, P. J., \& Weinberger, D. R. (2005). Schizophrenia genes, gene expression, and neuropathology: on the matter of their convergence. Molecular Psychiatry, 10(1), 40-68. image 45.

Hartwell, C. E. (1996). The schizophrenogenic mother concept in American psychiatry. Psychiatry, 59(3), 274-297.

Harvey, P. D., \& Keefe, R. S. E. (2001). Studies of cognitive change in patients with schizophrenia following novel antipsychotic treatment. American Journal of Psychiatry, 158 (2), 176-184.

Heaton, R. K. (1976). The validity of neuropsychological evaluations in psychiatric settings. Clinical Psychologist, 29(2), 10-11.

Heaton, R. K., Baade, L. E., \& Johnson, K. L. (1978). Neuropsychological test results associated with psychiatric disorders in adults. Psychological Bulletin, 85(1), 141-162.

Heaton, R. K., \& Drexler, M. (1987). Clinical neuropsychological findings in schizophrenia and aging. In E. Miller \& G. Cohen (Eds.), Schizophrenia and aging (pp. 145-161). New York: The Guilford Press.

Heaton, R. K., Gladsjo, J. A., Palmer, B. W., Kuck, J., Marcotte, T. D., \& Jeste, D. V. (2001). The stability and course of neuropsychological deficits in schizophrenia. Archives of General Psychiatry, 58(1), 24-32.

Heaton, R. K., Grant, I., Anthony, W. Z., \& Lehman, R. A. (1981). A comparison of clinical and automated interpretation of the Halstead-Reitan Battery. Journal of Clinical Neuropsychology, 3(2), 121-141.

Heaton, R. K., Paulsen, J. S., McAdams, L. A., Kuck, J., Zisook, S., Braff, D., et al. (1994). Neuropsychological deficits in schizo- schizophrenics: relationship to age, chronicity, and dementia. Archives of General Psychiatry, 51(6), 469-476.

Heaton, R. K., \& Pendleton, M. G. (1981). Use of neuropsychological tests to predict adult patients' everyday functioning. Journal of Consulting and Clinical Psychology, 49(6), 807-821.

Heinrichs, R. W., \& Awad, A. G. (1993). Neurocognitive subtypes of chronic schizophrenia. Schizophrenia Research, 9(1), 49-58.

Heinrichs, R. W., Miles, A. A., Smith, D., Zargarian, T., Vaz, S. M., Goldberg, J. O., et al. (2008). Cognitive, clinical, and functional characteristics of verbally superior schizophrenia patients. Neuropsychology, 22(3), 321-328.

Heinrichs, R. W., Ruttan, L., Zakzanis, K. K., \& Case, D. (1997). Parsing schizophrenia with neurocognitive tests: evidence of stability and validity. Brain and Cognition, 35(2), 207-224.

Heinrichs, R. W., \& Zakzanis, K. K. (1998). Neurocognitive deficit in schizophrenia: a quantitative review of the evidence. Neuropsychology, 12(3), 426-445.

Hill, S. K., Ragland, J. D., Gur, R. C., \& Gur, R. E. (2002). Neuropsychological profiles delineate distinct profiles of schizophrenia, an interaction between memory and executive function, and uneven distribution of clinical subtypes. Journal of Clinical and Experimental Neuropsychology, 24(6), 765-780.

Hill, S. K., Schuepbach, D., Herbener, E. S., Keshavan, M. S., \& Sweeney, J. A. (2004). Pretreatment and longitudinal studies of neuropsychological deficits in antipsychotic-naïve patients with schizophrenia. Schizophrenia Research, 68(1), 49-63.

Hippius, H. (1999). A historical perspective of clozapine. Journal of Clinical Psychiatry, 60(Suppl 12), 22-23.

Hollingshead, A. B., \& Redlich, F. C. (1958). Social class and mental illness: A community study. NY: Wiley.

Holthausen, E. A., Wiersma, D., Sitskoorn, M. M., Hijman, R., Dingemans, P. M., Schene, A. H., et al. (2002). Schizophrenic patients without neuropsychological deficits: subgroup, disease severity or cognitive compensation? Psychiatry Research, 112(1), $1-11$.

Horan, W. P., \& Goldstein, G. (2003). A retrospective study of premorbid ability and aging differences in cognitive clusters of schizophrenia. Psychiatry Research, 118(3), 209-221.

Ilonen, T., Taiminen, T., Karlsson, H., Lauerma, H., Leinonen, K.-M., Wallenius, E., et al. (2004). Neuropsychological subtyping of schizophrenia. Psychiatry Research, 129(2), 191-199.

Insel, T. R. (2009). Translating scientific opportunity into public health impact: a strategic plan for research on mental illness. Archives of General Psychiatry, 66(2), 128-133.

Jeste, D. V., Palmer, B. W., \& Harris, M. J. (1999). Neuroleptic discontinuation in clinical and research settings: scientific issues and ethical dilemmas. Biological Psychiatry, 46(8), 1050-1059.

Kee, K. S., Kern, R. S., \& Green, M. F. (1998). Perception of emotion and neurocognitive functioning in schizophrenia: what's the link? Psychiatry Research, 81(1), 57-65.

Keefe, R. S. E., Bilder, R. M., Davis, S. M., Harvey, P. D., Palmer, B. W., Gold, J. M., et al. (2007). Neurocognitive effects of antipsychotic medications in patients with chronic schizophrenia in the CATIE Trial. Archives of General Psychiatry, 64(6), 633-647.

Keefe, R. S. E., Eesley, C. E., \& Poe, M. P. (2005). Defining a cognitive function decrement in schizophrenia. Biological Psychiatry, 57(6), 688-691.

Keefe, R. S. E., Silva, S. G., Perkins, D. O., \& Lieberman, J. A. (1999). The effects of atypical antipsychotic drugs on neurocognitive impairment in schizophrenia: a review and metaanalysis. Schizophrenia Bulletin, 25(2), 201-222.

Keshavan, M. S., Tandon, R., Boutros, N. N., \& Nasrallah, H. A. (2008). Schizophrenia, "just the facts": what we know in 2008: Part 3: neurobiology. Schizophrenia Research, 106(2-3), 89-107.

Klingberg, S., Wittorf, A., Sickinger, S., Buchkremer, G., \& Wiedemann, G. (2008). Course of cognitive functioning during 
the stabilization phase of schizophrenia. Journal of Psychiatric Research, 42(4), 259-267.

Kraepelin, E. (1971/1919/1913). Dementia praecox and paraphrenia [Translated in 1919 from the eighth German edition of the "Textbook of psychiatry," vol. iii, part ii., section on Endogenous Dementias published in 1913]. New York: Krieger.

Kremen, W. S., Seidman, L. J., Faraone, S. V., Toomey, R., \& Tsuang, M. T. (2000). The paradox of normal neuropsychological function in schizophrenia. Journal of Abnormal Psychology, 109(4), 743-752.

Kremen, W. S., Lyons, M. J., Boake, C., Xian, H., Jacobson, K. C., Waterman, B., et al. (2006). A discordant twin study of premorbid cognitive ability in schizophrenia. Journal of Clinical and Experimental Neuropsychology, 28(2), 208-224.

Kubicki, M., McCarley, R., Westin, C. F., Park, H. J., Maier, S., Kikinis, R., et al. (2007). A review of diffusion tensor imaging studies in schizophrenia. Journal of Psychiatric Research, 41(1-2), 15-30.

Kurtz, M. M. (2005). Neurocognitive impairment across the lifespan in schizophrenia: an update. Schizophrenia Research, 74(1), 15-26.

Kurtz, M. M. (2006). Symptoms versus neurocognitive skills as correlates of everyday functioning in severe mental illness. Expert Review of Neurotherapeutics, 6(1), 47-56.

Lange, R. T., Iverson, G. L., Senior, G. J., \& Chelune, G. J. (2002). A primer on cluster analysis applications to cognitive rehabilitation research. Journal of Cognitive Rehabilitation, 20(1), 16-33.

Lawrie, S., McIntosh, A., Hall, J., Owens, D., \& Johnstone, E. (2008). Brain structure and function changes during the development of schizophrenia: the evidence from studies of subjects at increased genetic risk. Schizophrenia Bulletin, 34(2), 330-340.

Lebowitz, B. K., Shear, P. K., Steed, M. A., \& Strakowski, S. M. (2001). Verbal fluency in mania: relationship to number of manic episodes. Neuropsychiatry, Neuropsychology, and Behavioral Neurology, 14(3), 177-182.

Leonberger, F. T. (1989). The question of organicity: is it still functional? Professional Psychology: Research and Practice, 20 (6), 411-414.

Leung, W. W., Bowie, C. R., \& Harvey, P. D. (2008). Functional implications of neuropsychological normality and symptom remission in older outpatients diagnosed with schizophrenia: a cross-sectional study. Journal of the International Neuropsychological Society, 14(3), 479-488.

Levin, S., Yurgelun-Todd, D., \& Craft, S. (1989). Contributions of clinical neuropsychology to the study of schizophrenia. Journal of Abnormal Psychology, 98(4), 341-356.

Liu, S. K., Hsieh, M. H., Huang, T. J., Liu, C. M., Liu, C. C., Hua, M. S., et al. (2006). Patterns and clinical correlates of neuropsychologic deficits in patients with schizophrenia. Journal of the Formosan Medical Association, 105(12), 978-991.

Lothrop, W. W. (1961). A critical review of research on the conceptual thinking of schizophrenics. Journal of Nervous and Mental Disease, 132, 118-126.

MacLeod, C. M. (1991). Half a century of research on the Stroop effect: an integrative review. Psychological Bulletin, 109(2), 163-203.

Marder, S. R. (2006). Drug initiatives to improve cognitive function. Journal of Clinical Psychiatry, 67(Suppl 9), 31-35. discussion $36-42$.

Martinez-Aran, A., Vieta, E., Colom, F., Torrent, C., Sanchez-Moreno, J., Reinares, M., et al. (2004a). Cognitive impairment in euthymic bipolar patients: implications for clinical and functional outcome. Bipolar Disorders, 6(3), 224-232.

Martinez-Aran, A., Vieta, E., Reinares, M., Colom, F., Torrent, C., Sanchez-Moreno, J., et al. (2004b). Cognitive function across manic or hypomanic, depressed, and euthymic states in bipolar disorder. American Journal of Psychiatry, 161(2), 262-270.

Marwick, K., \& Hall, J. (2008). Social cognition in schizophrenia: a review of face processing. British Medical Bulletin, 88(1), 43-58.
May, J. V. (1931). The dementia praecox-schizophrenia problem. American Journal of Psychiatry, 11(3), 401-446.

McGuire, P., Howes, O., Stone, J., \& Fusar-Poli, P. (2008). Functional neuroimaging in schizophrenia: diagnosis and drug discovery. Trends in Pharmacological Sciences, 29(2), 91-98.

McLachlan, G. J., \& Basford, K. E. (1988). Mixture models: inference and applications to clustering. New York: Dekker.

Medalia, A., \& Choi, J. (2009). Cognitive Remediation in Schizophrenia. Neuropsychology Review. doi:10.1007/s11065-009-9097-y

Mednick, S. A., \& Hollister, J. M. (Eds.). (1995). Neural development and schizophrenia: theory and research. New York Plenum Press.

Meltzer, H., \& McGurk, S. (1999). The effects of clozapine, risperidone, and olanzapine on cognitive function in schizophrenia. Schizophrenia Bulletin, 25(2), 233-255.

Mesholam-Gately, R. I., Giuliano, A. J., Goff, K. P., Faraone, S. V., \& Seidman, L. J. (2009). Neurocognition in first-episode schizophrenia: a meta-analytic review. Neuropsychology, 23(3), 315-336.

Mischel, W. (1973). Toward a cognitive social learning reconceptualization of personality. Psychological Review, 80(4), 252-283.

Mishara, A. L., \& Goldberg, T. E. (2004). A meta-analysis and critical review of the effects of conventional neuroleptic treatment on cognition in schizophrenia: opening a closed book. Biological Psychiatry, 55(10), 1013-1022.

Nayak, G. V., Moore, D. J., Roesch, S. C., Jeste, D. V., Heaton, R. K., \& Palmer, B. W. (2006). An evaluation of longitudinal neurocognitive performance among middle-aged and older schizophrenia patients: use of mixed-model analyses. Schizophrenia Research, 83, 215-223.

Palmer, B. W., Heaton, R. K., Gladsjo, J. A., Evans, J. D., Patterson, T. L., Golshan, S., et al. (2002). Heterogeneity in functional status among older outpatients with schizophrenia: employment history, living situation, and driving. Schizophrenia Research, 55 (3), 205-215.

Palmer, B. W., Heaton, R. K., Paulsen, J. S., Kuck, J., Braff, D., Harris, M. J., et al. (1997). Is it possible to be schizophrenic yet neuropsychologically normal? Neuropsychology, 11(3), 437-446.

Palmer, B. W., \& Jeste, D. V. (2006). Relationship of individual cognitive abilities to specific components of decisional capacity among middle-aged and older patients with schizophrenia. Schizophrenia Bulletin, 32(1), 98-106.

Palmer, B. W., \& Savla, G. N. (2009). Neuropsychological deficits in schizoaffective disorder. In K. S. Yip (Ed.), Schizoaffective disorders: International perspectives on understanding, intervention and rehabilitation (pp. 115-134). New York: Nova Science.

Paris, J. (2005). The fall of an icon: Psychoanalysis and academic psychiatry. Toronto: University of Toronto Press.

Partington, J. E., \& Leiter, R. G. (1949). Partington's Pathways Test. The Psychological Service Center Journal, 1(2), 9-20.

Paulsen, J. S., Heaton, R. K., Sadek, J. R., Perry, W., Delis, D. C., Braff, D., et al. (1995). The nature of learning and memory impairments in schizophrenia. Journal of the International Neuropsychological Society, 1(1), 88-99.

Payne, R. W., Mattussek, P., \& George, E. I. (1959). An experimental study of schizophrenic thought disorder. Journal of Mental Science, 105(440), 627-652.

Pijnenborg, G. H., Withaar, F. K., Evans, J. J., van den Bosch, R. J., Timmerman, M. E., \& Brouwer, W. H. (2009). The predictive value of measures of social cognition for community functioning in schizophrenia: implications for neuropsychological assessment. Journal of the International Neuropsychological Society, 15(2), 239-247.

Price, G., Cercignani, M., Parker, G. J. M., Altmann, D. R., Barnes, T. R. E., Barker, G. J., et al. (2007). Abnormal brain connectivity in first-episode psychosis: a diffusion MRI tractography study of the corpus callosum. Neuroimage, 35(2), 458-466. 
Ragland, J. D., Yoon, J., Minzenberg, M. J., \& Carter, C. S. (2007). Neuroimaging of cognitive disability in schizophrenia: search for a pathophysiological mechanism. International Review of Psychiatry, 19(4), 417-427.

Rajji, T. K., \& Mulsant, B. H. (2008). Nature and course of cognitive function in late-life schizophrenia: a systematic review. Schizophrenia Research, 102(1-3), 122-140.

Rapoport, J. L., Addington, A. M., Frangou, S., \& Psych, M. R. C. (2005). The neurodevelopmental model of schizophrenia: update 2005. Molecular Psychiatry, 10(5), 434-449.

Rawlings, E. (1921). The intellectual status of patients with paranoid dementia praecox: its relation to organic brain changes. Archives of Neurology and Psychiatry, 5, 283-295.

Reichenberg, A., \& Harvey, P. (2007). Neuropsychological impairments in schizophrenia: integration of performance-based and brain imaging findings. Psychological Bulletin, 133(5), 833858.

Rotter, J. B. (1966). Generalized expectancies for internal versus external control of reinforcement. Psychological Monographs: General \& Applied, 80(1), 1-28.

Rund, B. R. (1998). A review of longitudinal studies of cognitive functions in schizophrenia patients. Schizophrenia Bulletin, 24 (3), 425-435.

Satz, P. (1993). Brain reserve capacity on symptom onset after brain injury: a formulation and review of evidence for threshold theory. Neuropsychology, 7(3), 273-295.

Schretlen, D. J., Cascella, N. G., Meyer, S. M., Kingery, L. R., Testa, S. M., Munro, C. A., et al. (2007). Neuropsychological functioning in bipolar disorder and schizophrenia. Biological Psychiatry, 62(2), 179-186.

Schwartzman, A. E., \& Douglas, V. I. (1962). Intellectual loss in schizophrenia. I. Canadian Journal of Psychology, 16, 1-10.

Schwartzman, A. E., Douglas, V. I., \& Muir, W. R. (1962). Intellectual loss in schizophrenia II. Canadian Journal of Psychology, 16, $161-168$.

Seaton, B. E., Allen, D. N., Goldstein, G., Kelley, M. E., \& van Kammen, D. P. (1999). Relations between cognitive and symptom profile heterogeneity in schizophrenia. Journal of Nervous and Mental Disease, 187(7), 414-419.

Seaton, B. E., Goldstein, G., \& Allen, D. N. (2001). Sources of heterogeneity in schizophrenia: the role of neuropsychological functioning. Neuropsychology Review, 11(1), 45-67.

Seidman, L. J., Buka, S. L., Goldstein, J. M., \& Tsuang, M. T. (2006). Intellectual decline in schizophrenia: evidence from a prospective birth cohort 28 year follow-up study. Journal of Clinical and Experimental Neuropsychology, 28(2), 225-242.

Seidman, L. J., Kremen, W. S., Koren, D., Faraone, S. V., Goldstein, J. M., \& Tsuang, M. T. (2002). A comparative profile analysis of neuropsychological functioning in patients with schizophrenia and bipolar psychoses. Schizophrenia Research, 53(1-2), 31-44.

Shad, M. U., Tamminga, C. A., Cullum, M., Haas, G. L., \& Keshavan, M. S. (2006). Insight and frontal cortical function in schizophrenia: a review. Schizophrenia Research, 86(1-3), 54-70.

Shenton, M., Dickey, C., Frumin, M., \& McCarley, R. (2001). A review of MRI findings in schizophrenia. Schizophrenia Research, 49(1-2), 1-52.

Silverstein, M. L., \& Zerwic, M. J. (1985). Clinical psychopathologic symptoms in neuropsychologically impaired and intact schizophrenics. Journal of Consulting and Clinical Psychology, 53(2), 267-268.

Spielmeyer, W. (1930). The problem of the anatomy of schizophrenia. Journal of Nervous and Mental Disease, 73(3), 241-244.

Spohn, H. E., \& Strauss, M. E. (1989). Relation of neuroleptic and anticholinergic medication to cognitive functions in schizophrenia. Journal of Abnormal Psychology, 98(4), 367-380.
Squire, L. R. (2004). Memory systems of the brain: a brief history and current perspective. Neurobiology of Learning and Memory, 82 (3), 171-177.

Stern, Y. (2002). What is cognitive reserve? Theory and research application of the reserve concept. Journal of the International Neuropsychological Society, 8(3), 448-460.

Strauss, B. S., \& Silverstein, M. L. (1986). Luria-Nebraska measures in neuropsychologically nonimpaired schizophrenics: a comparison with normal subjects. The International Journal of Clinical Neuropsychology, 8(1), 35-38.

The Psychological Corporation. (1997). WAIS-III/WMS-III technical manual. San Antonio: The Psychological Corporation.

Torrent, C., Martinez-Aran, A., Daban, C., Sanchez-Moreno, J., Comes, M., Goikolea, J. M., et al. (2006). Cognitive impairment in bipolar II disorder. British Journal of Psychiatry, 189, 254-259.

Torrey, E. F., Bowler, A. E., Taylor, E. H., \& Gottesman, I. I. (1994). Schizophrenia and manic-depressive disorder: The biological roots of mental illness as revealed by the landmark study of identical twins. New York: Basic Books.

Tröster, A. I., Butters, N., Salmon, D. P., Cullum, C. M., Jacobs, D., Brandt, J., et al. (1993). The diagnostic utility of savings scores: differentiating Alzheimer's and Huntington's diseases with the logical memory and visual reproduction tests. Journal of Clinical and Experimental Neuropsychology, 15(5), 773-788.

Twamley, E. W., Doshi, R. R., Nayak, G. V., Palmer, B. W., Golshan, S., Heaton, R. K., et al. (2002). Generalized cognitive impairments, ability to perform everyday tasks, and level of independence in community living situations of older patients with psychosis. American Journal of Psychiatry, 159(12), 2013-2020.

Twamley, E. W., Jeste, D. V., \& Bellack, A. S. (2003). A review of cognitive training in schizophrenia. Schizophrenia Bulletin, 29 (2), 359-382.

Twamley, E. W., Savla, G. N., Zurhellen, C. H., Heaton, R. K., \& Jeste, D. V. (2008). Development and pilot testing of a novel compensatory cognitive training intervention for people with psychosis. American Journal of Psychiatric Rehabilitation, 11(2), 144-163.

Vahia, I., Bankole, A. O., Reyes, P., Diwan, S., Palekar, N., Sapra, M., et al. (2007). Schizophrenia in later life. Aging Health, 3(3), 383-396.

Vauth, R., Rüsch, N., Wirtz, M., \& Corrigan, P. W. (2004). Does social cognition influence the relation between neurocognitive deficits and vocational functioning in schizophrenia? Psychiatry Research, 128(2), 155-165.

Velligan, D. I., Bow-Thomas, C. C., Mahurin, R. K., Miller, A. L., \& Halgunseth, L. C. (2000). Do specific neurocognitive deficits predict specific domains of community function in schizophrenia? Journal of Nervous and Mental Disease, 188 (8), 518-524.

Velligan, D. I., Kern, R. S., \& Gold, J. M. (2006). Cognitive rehabilitation for schizophrenia and the putative role of motivation and expectancies. Schizophrenia Bulletin, 32(3), 474-485.

Vigotsky, L. S. (1934). Thought in schizophrenia. Archives of Neurology and Psychiatry, 31, 1063-1077.

Walker, E., \& Tessner, K. (2008). Schizophrenia. Perspectives on Psychological Science. Special Issue: From philosophical thinking to psychological empiricism, 3(1), 30-37.

Walterfang, M., Wood, A. G., Reutens, D. C., Wood, S. J., Chen, J., Velakoulis, D., et al. (2008). Morphology of the corpus callosum at different stages of schizophrenia: cross-sectional study in firstepisode and chronic illness. British Journal of Psychiatry, 192(6), 429-434.

Ward, J. H. (1963). Hierarchical groupings to optimize an objective function. Journal of the American Statistical Association, 58, 234-244.

Watson, C. G., Thomas, R. W., Andersen, D., \& Felling, J. (1968) Differentiation of organics from schizophrenics at two chronicity 
levels by use of the Reitan-Halstead organic test battery. Journal of Consulting and Clinical Psychology, 32(6), 679-684.

Wechsler, D. (1939). The measurement of adult intelligence. Baltimore: Williams \& Wilkins Co.

Weickert, T. W., Goldberg, T. E., Gold, J. M., Bigelow, L. B., Egan, M. F., \& Weinberger, D. R. (2000). Cognitive impairments in patients with schizophrenia displaying preserved and compromised intellect. Archives of General Psychiatry, 57(9), 907-913.

Weinberg, S. M., Jenkins, E. A., Marazita, M. L., \& Maher, B. S. (2007). Minor physical anomalies in schizophrenia: a metaanalysis. Schizophrenia Research, 89(1-3), 72-85.

Wexler, B., Zhu, H., Bell, M., Nicholls, S., Fulbright, R., Gore, J., et al. (2009). Neuropsychological near normality and brain structure abnormality in schizophrenia. American Journal of Psychiatry, 166(2), 189-195.

White, L., Friedman, J. I., Bowie, C. R., Evers, M., Harvey, P. D., Parrella, M., et al. (2006). Long-term outcomes in chronically hospitalized geriatric patients with schizophrenia: retrospective comparison of first generation and second generation antipsychotics. Schizophrenia Research, 88(1-3), 127-134.

Wilk, C. M., Gold, J. M., McMahon, R. P., Humber, K., Iannone, V. N., \& Buchanan, R. W. (2005). No, it is not possible to be schizophrenic yet neuropsychologically normal. Neuropsychology, 19(6), 778-786.

Winterer, G., Coppola, R., Egan, M. F., Goldberg, T. E., \& Weinberger, D. R. (2003). Functional and effective frontotempo- ral connectivity and genetic risk for schizophrenia. Biological Psychiatry, 54(11), 1181-1192.

Wittman, M. P. (1937). An evaluation of opposed theories concerning the etiology of so-called "dementia" in dementia praecox. American Journal of Psychiatry, 93(6), 1363-1377.

Woodberry, K. A., Giuliano, A. J., \& Seidman, L. J. (2008). Premorbid IQ in schizophrenia: a meta-analytic review. American Journal of Psychiatry, 165(5), 579-587.

Woodward, N. D., Purdon, S. E., Meltzer, H. Y., \& Zald, D. H. (2005). A meta-analysis of neuropsychological change to clozapine, olanzapine, quetiapine, and risperidone in schizophrenia. International Journal of Neuropsychopharmacology, 8 (3), 457-472.

Woodward, N. D., Purdon, S. E., Meltzer, H. Y., \& Zald, D. H. (2007). A meta-analysis of cognitive change with haloperidol in clinical trials of atypical antipsychotics: dose effects and comparison to practice effects. Schizophrenia Research, 89(1-3), 211-224.

Wright, D. M. (1975). Impairment in abstract conceptualization in schizophrenia. Psychological Bulletin, 82(1), 120-127.

Zec, R. F. (1995). Neuropsychology of schizophrenia according to Kraepelin: disorders of volition and executive functioning. European Archives of Psychiatry and Clinical Neuroscience, 245(4-5), 216-223.

Zubieta, J. K., Huguelet, P., O’Neil, R. L., \& Giordani, B. J. (2001). Cognitive function in euthymic bipolar I disorder. Psychiatry Research, 102(1), 9-20.

Zubin, J., \& Spring, B. (1977). Vulnerability - new view of schizophrenia. Journal of Abnormal Psychology, 86(2), 103-126. 